\title{
Petrography, composition, and origin of large, chromian spinels from the Murchison meteorite
}

\author{
S. B. Simon, ${ }^{1}$ L. Grossman, ${ }^{1,2}$ F. A. Podosek, ${ }^{3,4}$ E. Zinner, ${ }^{3,5}$ and C. A. Prombo ${ }^{3,4}$ \\ ${ }^{1}$ Departinent of Geophysical Sciences, The University of Chicago, 5734 South Ellis Avenue, Chicago, IL 60637, USA \\ ${ }^{2}$ Enrico Fermi Institute, The University of Chicago, 5630 South Ellis Avenue, Chicago, IL 60637. USA \\ ${ }^{3}$ McDonnell Center for the Space Sciences, Washington University, One Brookings Drive, St. Louis, MO 63130-4899, USA \\ ${ }^{4}$ Department of Earth and Planetary Sciences, Washington University, St. Louis. MO 63130, USA \\ ${ }^{5}$ Department of Physics, Washington University, St. Louis, MO 63130, USA
}

(Received March 2, 1993; accepted in revised form Seplember 24, 1993)

\begin{abstract}
Most spinel grains in Murchison acid residues are Mg-, Al-rich, ${ }^{16} \mathrm{O}$-rich $\left(\delta^{18} \mathrm{O}=-50 \%\right)$, small $(10-30 \mu \mathrm{m})$ and probably from refractory inclusions. They are quite unlike spinels we have recovered from Murchison by freeze-thaw disaggregation, density separation, and handpicking. As reported here, the latter spinels contain up to $37 \mathrm{wt} \% \mathrm{Cr}_{2} \mathrm{O}_{3}$ and up to $17 \mathrm{wt} \% \mathrm{FeO}$, are not ${ }^{16} \mathrm{O}$-enriched $\left(\delta^{18} \mathrm{O}=1.9\right.$ $\pm 2.4 \%)$, are coarse $(60-325 \mu \mathrm{m})$, and are not from refractory inclusions. From backscattered electron images of fifty-seven such grains, we recognize five zoning types defined by variations in $\mathrm{Cr}_{2} \mathrm{O}_{3}$ contents: patchy $(56 \%)$; homogeneous $(21 \%)$; chevron $(10.5 \%)$; gradational (9\%); and core-rim (3.5\%). Many grains have silicate inclusions, the most common being small, anhedral grains of diopside with 12-24 wt $\% \mathrm{Al}_{2} \mathrm{O}_{3}$ and up to $3.7 \mathrm{wt} \% \mathrm{TiO}_{2}$. Eleven spinel samples occur with forsteritic ( Fo $\mathrm{g}_{9-99}$ ) olivine; in most cases, the spinel partially encloses the olivine. Cr-bearing spinel was found in situ in two Al-rich chondrules (one with homogeneous spinel, the other with homogeneous, gradational and core-rim spinel, and both with forsterite and aluminous diopside); in two irregularly shaped, olivine-bearing inclusions (one with homogeneous spinel, the other patchy); and attached to an isolated olivine grain (patchy). Observation of homogeneous, gradational, and core-rim type spinels in chondrules and basalts shows that grains with these zoning patterns can crystallize from liquids, although, in Murchison, chondrules with the appropriate compositions and sufficiently coarse textures to yield the separated spinels are exceedingly rare. Chevronzoned grains also could have formed in chondrules; alternatively, they may have acquired their oscillatory zoning patterns by cycling through different $P-T-f_{\mathrm{O}_{2}}$ regimes in the solar nebula during their formation. The patchy spincl grains were probably never molten and they most likely formed by sintering of aggregates of smaller spinel grains which were enriched in $\mathrm{Cr}$ and Fe to varying degrees. In spite of their various crystallization and thermal histories, the spinels all have normal oxygen and chromium isotopic compositions, consistent with formation from a single, well-mixed nebular reservoir. Based on the known slow rates of diffusion of oxygen in $\mathrm{MgO}, \mathrm{Al}_{2} \mathrm{O}_{3}$, and $\mathrm{MgAl}_{2} \mathrm{O}_{4}$, it is unlikely that the spinels of this study formed from an isotopically anomalous reservoir and later re-equilibrated with a normal one; it is more likely that they have retained their original isotopic compositions. We see no evidence for anomalous $\mathrm{Cr}$, which had been reported by others.
\end{abstract}

\section{INTRODUCTION}

SPINEL GRAINS FROM the Murchison (CM2) meteorite have been of interest ever since CLAYTON and MAYEDA (1984) reported large ${ }^{16} \mathrm{O}$ enrichments $\left(\delta^{18} \mathrm{O}=-40 \%\right.$ ) in a bulk, spinel-rich aliquot of acid residue 2C10c. ZINNER and EP. STEIN (1986) found large ${ }^{13} \mathrm{C}$ excesses in spinel grains from Murchison acid residue CFOc and, at the time, could not rule out the possibility that the anomalous $C$ was truly incorporated in the spinel. This led KUEHNER and GROSSMAN (1987) to study spinel grains recovered from Murchison by freeze-thaw disaggregation, heavy liquid (density) separation, and handpicking, with the goal of petrographically characterizing the spinels with isotopically anomalous carbon. Ion probe analysis of the grains described by KUEHNER and GrossmAN ( 1987) showed, however, that they have isotopically normal carbon and oxygen (GROSSMAN et al., 1988). An additional, important difference between the handpicked spinel grains and those in the acid residues is that the former are coarse: $60-325 \mu \mathrm{m}$ vs. $3-50 \mu \mathrm{m}$ (but mostly $3-10 \mu \mathrm{m}$ ) in 2C10c and $10-30 \mu \mathrm{m}$ in CFOc. Unlike CLAYTON and
MAYEDA (1984), who analyzed a bulk separate, VIRAG et al. (1991) used an ion probe to measure oxygen isotopic compositions of individual grains of spinel recovered from Murchison acid residue CFOc. They found that grains of pure $\mathrm{Mg}$-, Al-spinel had even greater ${ }^{16} \mathrm{O}$ enrichments $\left(\delta^{18} \mathrm{O}\right.$ $=-50 \%$ ) than the residue analyzed by CLAYTON and MAYEDA (1984). VIRAG et al. (1991) concluded that the Mg-rich spinel grains which they analyzed belong to an ${ }^{16} \mathrm{O}$-rich population, the relatively $\mathrm{Cr}$-rich ( up to $37 \mathrm{w}(\%) \mathrm{Cr}_{2} \mathrm{O}_{3}$ vs. $<5900$ ppm in the CFOc grains) spinel analyzed by GROSSMAN et al. (1988) represent an ${ }^{16} \mathrm{O}$-poor group, and the spinel analyzed by CLAYTON and MAYEDA (1984) is a mixture of the two.

Chromium isotopic analyses may also indicate that there are two types of spinel in Murchison. Spinels in common refractory inclusions are characterized by modest but wellestablished and endemic ${ }^{54} \mathrm{Cr}$ excesses of 5-10 $\epsilon$-units (parts in $10^{4}$ ) and ${ }^{53} \mathrm{Cr}$ deficits of $1-2 \epsilon$-units, relative to assumed normal ${ }^{50} \mathrm{Cr} /{ }^{52} \mathrm{Cr}$ (PAPANASTASSIOU, 1986; BIRCK and ALLÈGRE, 1988). In contrast, ESAT and IRELAND (1989) reported much larger (several permil) and variable chromium 
isotopic anomalies in Murchison spinels of the type considered here, which would suggest that these spinels formed from a much narrower class of presolar materials than the spinels from refractory inclusions.

The ${ }^{16} \mathrm{O}$-rich, Mg-, Al-spinels are probably from refractory inclusions (MACPIICRSON et al, 1983, 1984a; IRELAND et al. 1992), but little is known about the origin of the ${ }^{16} \mathrm{O}$ poor, $\mathrm{Cr}$-bearing spinels. These grains are the subject of the present study, in which we use detailed petrographic, mineralchemical, and isotopic ( $\mathrm{O}$ and $\mathrm{Cr}$ ) data to constrain their origins and histories. Some preliminary results of this study were reported by KUEHNER and GROSSMAN (1987). GROSSMAN et al. (1988), PODOSEK et al. (1991), and SIMON and Grossman (1992). Also, MaCPHERson et al. (1983) studied samples SP2-SP7, which are included in the present suite of samples.

\section{ANALYTICAL TECHNIQUES}

\section{Sample Preparation, Scanning Electron Microscopy, and Electron Probe Microanalysis}

Chips of Murchison were disaggregated using the freeze-thaw method described by MACPHERSON et al. (1980). Spinel grains were handpicked from the densest fraction $(\rho>3.50)$, examined with a binocular microscope, and identified on the basis of color (pink, red, or purple), high refractive index and, where possible, octahedral shape (KUEHNER and GROSSMAN, 1987). Some grains were split, with separate chips used for ion microprobe and thermal ionization mass spectrometric analysis and another mounted in epoxy for petrographic study. Other grains (SP51-SP81) were not split and were only mounted in epoxy. Six grains (SP22, SP25, SP26, SP32. SP34, and SP35) were either plucked or not sufficiently polished for petrographic study. Polished sections of all remaining fifty-seven grains were examined with a JEOL JSM-35 scanning electron microscope (SEM) operated at $10 \mathrm{kV}$ and $2-3 \mathrm{nA}$. This relatively high current was used to obtain increased contrast in backscattered electron images (BEI), revealing smaller composition variations within spinel grains than can be observed at normal operating currents. Wavelength-dispersive analyses of spinel and attached phases were performed with a fully automated Cameca SX-50 electron microprobe. Synthetic glass and crystal (spinel, thortveitite, rutile, $\mathrm{Cr}_{2} \mathrm{O}_{3}$ ) and natural mineral ( $\mathrm{P}$. 140 olivine, andradite) standards were used. Except for the analyses plotted in Fig. 5, which were all collected at $15 \mathrm{kV}$ and $40 \mathrm{nA}$, data for major elements were collected at $15 \mathrm{kV}$ with a beam current of $25 \mathrm{nA}$, and for minor elements (e.g., Ti and $\mathrm{V}$ in spinel and olivine) at $25 \mathrm{kV}$ and $200 \mathrm{nA}$. This was done with an automated routine in which each point was analyzed for major elements, then the accelerating voltage and beam current settings needed for minor element analysis were loaded automatically, and the same point was analyzed for trace elements without moving the stage. Background count rates were measured at offsets below and above each peak position for a total counting time equal to that used for the peak. Data were reduced via the modified ZAF correction procedure PAP (POUCHOU and PICHOIR, 1984).

\section{Ion Microprobe Analysis}

For the oxygen isotopic measurements, fragments of spinel crystals were pressed into gold foil along with Burma spinel (USNM\#135273), a terrestrial standard whose isotopic composition had previously been determined to be $\delta^{17} \mathrm{O}_{\text {SMOW }}=+11.6 \%$ and $\delta^{18} \mathrm{O}_{\text {SMOw }}=+22.1 \%$ by conventional gas mass spectrometry ( $R$. N. CLAYTON and T. $K$. MAYEDA, pers. commun.). The technique for oxygen isotopic analysis with the Washington University ion microprobe, a modified CAMECA IMS 3F, has previously been described by MCKEEGAN (1987), FAHEY et al. (1987), and VIRAG et al. (1991). Oxygen was detected as negative secondary ions produced by $\mathrm{Cs}^{+}$bombardment. A mass resolving power of 6500 was sufficient to resolve ${ }^{17} \mathrm{O}^{-}$from ${ }^{16} \mathrm{OH}^{-}$. Measurements on Murchison spinel samples were interspersed with measurements on the terrestrial standard. The meteoritic data wets normalized by comparing the average of the Burma spincl data to the known composition of this standard.

\section{Thermal Ionization Mass Spectrometry}

Splits of some of the same grains that were analyzed for oxygen isotopes were also analyzed for chromium isotopes. For chromium isotopic analysis we used a "direct-load" procedure in which spinel grain fragments were loaded with silica gel and boric acid onto $\mathrm{V}$ shaped Re mass spectrometer filaments. Isotopic analyses were performed in the Washington University VG-354 thermal ionization mass spectrometer; all measurements were made with a Daly detector operated in pulse-counting mode. As calibrations for $\mathrm{Cr}$. we used the same Burma spinel employed for calibration of the ion probe oxygen analyses and also a reagent $\mathrm{Cr}$ solution, both loaded the same way as the Murchison spinels. All data were acquired with a beam intensity of $\sim 2 \times 10^{5} \mathrm{cps}$ of ${ }^{52} \mathrm{Cr}$. Ion isotopic ratios were corrected for in strumental discrimination assuming terrestrial normal ${ }^{50} \mathrm{Cr} /{ }^{52} \mathrm{Cr}$ as reported by SHIELDS et al. (1966) and the "exponential" mass dependence described by Russel. et al. (1978). Results for ${ }^{53} \mathrm{Cr}$ and ${ }^{54} \mathrm{Cr}$ abundances are reported as $\mathrm{t}$-unit deviations from the terrestrial normal composition reported by PAPANASTASSIOU (1986).

Potential isobaric interferences from ${ }^{50} \mathrm{Ti}$ and ${ }^{54} \mathrm{Fe}$ were monitored at masses 49 and $56 \mathrm{amu}$, respectively, with formal corrections made assuming normal titanium and iron isotopic compositions. In practice. no Ti signal above a few counts per sceond was identifiably detected in any of these analyses, and the formal corrections based on mass 49 are trivial $(\leq 0.2 \epsilon)$. An Fe ion signal, monitored at mass 56 , was generally found to be present. In some analyses, the corresponding correction to ${ }^{54} \mathrm{Cr}$ was substantial (several hundred $t$ ). Even in such cases the corrected ${ }^{54} \mathrm{Cr} /{ }^{52} \mathrm{Cr}$ agreed as well as could be determined (i.e. within several $\epsilon$ ) with data acquired for the same sample during other parts of the analysis when the Fe interference was much lower. which gives us confidence that the 56 signal is correctly identified as $\mathrm{Fe}$. The data reported do not include any analyses involving an $\mathrm{Fe}$ correction greater than $10 \mathrm{\epsilon}$ and, for most of these data, the correction is substantially smaller (no more than a few + and in many cases $<1 \epsilon)$. We consider the uncertaint $t$ in the Fe correction not to be a significant contribution to overall uncertainty.

Data acquisition and reduction were organized into "sets," whers" each set comprises five cycles through the chromium isotopes, integrating for five seconds at each field setting, plus baseline and interference measurements. Beam intensity regulation, ion source focusing, magnetic ficld adjustments, and various diagnostics were performed between sets. A "run" is a collection of sets, up to a maximum of 100 sets, for which the isotope ratios of interest $\left({ }^{50} \mathrm{Cr} /{ }^{52} \mathrm{Cr} \cdot{ }^{53} \mathrm{Cr} /\right.$ ${ }^{52} \mathrm{Cr}$. and ${ }^{54} \mathrm{Cr} /{ }^{52} \mathrm{Cr}$ ) are taken as the means of the ratios calculated for each set, with uncertainties ("internal" errors) hased on the variances of the set ratios about their mean. Under ideal circumstances, when no other sources of error are important. precision in isotopic ratio measurement is limited by Poisson statistics for the number of ions detected. For the protocol described above, the one-sigma Poisson limits for one set, including the errors in the ${ }^{52} \mathrm{Cr}$ and ${ }^{50} \mathrm{Cr}$ measurements, are $18 \epsilon$ for ${ }^{53} \mathrm{Cr}$ and $34 \epsilon$ for ${ }^{54} \mathrm{Cr}$. Set-to-set variations agrec well with Poisson statistics. indicating no sources of error that ar: significant compared to internal statistics and that operate on a setto-set timescale.

The samples studied here were generally run to exhaustion, i.e. until they could no longer produce a satisfactory ion beam. This generally involved multiple runs, including repeat runs on the same filament load and more than one filament load for the same sample. The data reported in this paper, including those for reagent $\mathrm{Cr}$ and Burma spinel, are weighted means, and errors of the means, for all runs on a given sample. In aggregate, the data for Burma spinel are normal within formal errors, but the data for reagent $\mathrm{Cr}$ are not (Table 8). We take this as evidence for the presence of some source(s) of analytical error at a level which is not prominent compared to statistical errors for a single run but which becomes prominent when the statistical errors are formally reduced by convergence of the mean for a large number of runs (thirty-one runs for reagent $\mathrm{Cr}$ ). The nature of such sources of error is unknown; one possibility is secondorder mass dependence of instrumental discrimination, which might 
be especially relevant in comparing reagent on the one hand with direct-loaded solid crystals on the other. Probably the best estimate for systematic errors in this procedure for $\mathrm{Cr}$ analysis is provided by the degree to which the reagent $\mathrm{Cr}$ deviates from assumed normal, i.e., around $2 \epsilon$ for ${ }^{53} \mathrm{Cr}$ and $5 \epsilon$ for ${ }^{54} \mathrm{Cr}$, less than single-run statistical errors and much less than the size of the effects we wish to study here.

\section{SAMPLE DESCRIPTIONS}

\section{Zoning Patterns in Spinel}

When viewed with the binocular microscope, each spinel grain is translucent, uniform in color and luster, and completely homogeneous from one edge to the other. Some of these spinel grains are bounded by crystal faces, but not on all sides. When viewed at higher magnification with the petrographic microscope and SEM, the interiors of most samples are seen to contain few cracks or cavities whose presence would indicate polycrystallinity. Although the isotropism of spinel prevents optical confirmation, there is no indication that these grains are anything but single crystals, although some have attached grains and/or inclusions of phases other than spinel. There are perhaps four samples with inclusion or cavity patterns which suggest that those samples may consist of many small grains rather than one large crystal.

In backscattered electron images (BEIs), brightness correlates directly with the average atomic number of the sample, which, in the case of the spinel grains being considered here, depends mainly on the $\mathrm{Cr}_{2} \mathrm{O}_{3}$ (and, in some cases, $\mathrm{FeO}$ ) contents of the spinel. High-contrast $\mathrm{BEIs}$ of these samples can reveal composition differences as small as $\sim 2 w_{t} \% \mathrm{Cr}_{2} \mathrm{O}_{3}$. From examination of BEIs of each grain, we have recognized five different zoning patterns with respect to spatial variation of $\mathrm{Cr}_{2} \mathrm{O}_{3}$ contents. In addition, in most grains, increases in $\mathrm{Cr}_{2} \mathrm{O}_{3}$ are accompanied by increases in $\mathrm{Ti}$ ( reported as $\mathrm{TiO}_{2}$ ) and $\mathrm{V}_{2} \mathrm{O}_{3}$, but there is no systematic correlation with $\mathrm{Mg}$ / Fe. Petrographic and chemical features of each grain are summarized in Table 1 . In order of decreasing abundance, the zoning types are patchy $(56 \%)$, homogeneous $(21 \%)$, chevron $(10.5 \%)$, gradational $(9 \%)$, and core-rim $(3.5 \%)$. Each type is described below.

\section{Patchy'}

Four examples of this type are shown in Fig. 1a-d, and they illustrate some of the differences among grains of this type. Patchy grains are characterized by numerous islands, typically $10-20 \mu \mathrm{m}$ (but up to $100 \mu \mathrm{m}$ ) across, of contrasting $\mathrm{Cr}_{2} \mathrm{O}_{3}$ contents. In some grains, such as SP41 (Fig. Ia), the patches are rounded and irregularly shaped. In others, such as SP60 (Fig. 1b), the patches have relatively straight boundaries and are square to rectangular. Some have patches with sharp boundaries ( SP4 1 ) and others, like SP51 (Fig. Ic), do not. Some have patches evenly distributed throughout the grain, whereas in others, such as SP64 (Fig. 1d), the patches are concentrated in one part of the grain. Aluminous diopside inclusions, commonly associated with voids, are present in many of the patchy spinels and are discussed in a later section. Although there are aureoles (typically $\mathrm{Cr}$-poor) around the inclusions in a few grains, neither the inclusions nor the voids appear to be related, in general, to the distribution of patches within their host grains.
Table 1. Summary of characteristics of separated spinel grains.

\begin{tabular}{|c|c|c|c|c|c|c|}
\hline \multirow[b]{2}{*}{$\begin{array}{c}\text { Sample } \\
\text { No. }\end{array}$} & \multirow[b]{2}{*}{$\begin{array}{l}\mathrm{Cr}_{2} \mathrm{O}_{3} \\
\text { (range, } \\
\text { wt \%) }\end{array}$} & \multirow[b]{2}{*}{$\begin{array}{c}\text { FeO } \\
\text { (range, } \\
\text { wt \%) }\end{array}$} & \multicolumn{4}{|c|}{ 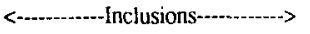 } \\
\hline & & & $\begin{array}{c}\text { Al- } \\
\text { Diop }\end{array}$ & Olivine & Glass & Other \\
\hline \multicolumn{7}{|l|}{ Patchy } \\
\hline SP2 & $23-25$ & 8 & $X$ & - & - & $\ldots$ \\
\hline SP4 & $7.3-13.7$ & 0.5 & $X$ & $\mathrm{x}$ & -- & $\mathrm{NiFe}$ \\
\hline SP6 & $3.5-5.2$ & 0.3 & $\mathrm{x}$ & $\mathrm{x}$ & - & -- \\
\hline SP7 & $12.0-16.5$ & 14 & $\mathrm{X}$ & - & -- & $\mathrm{Ca}-, \mathrm{F}$ \\
\hline SP23 & $1.7-5.4$ & 1.0 & $\mathrm{X}$ & $X$ & - & --- \\
\hline SP24 & $6.0-8.5$ & 0.6 & $\cdots$ & - & $\ldots$ & $\ldots$ \\
\hline SP30 & $0.6-3.0$ & 0.5 & $\mathrm{X}$ & -- & - & $\mathrm{Fe}-\mathrm{sil}$ \\
\hline SP31 & $9.0-18.0$ & $4.0-7.0$ & $\ldots$ & - & $\cdots$ & Fe-sil \\
\hline SP41 & $2.5-10.0$ & 0.5 & $\mathrm{X}$ & -- & - & --- \\
\hline $\mathrm{SP}^{2} 43$ & $16.0-23.0$ & 6.7 & -- & & -. & $\cdots$ \\
\hline SP46 & $.6-6.2$ & 0.3 & --- & -- & - & --- \\
\hline SP51 & $0.8-8.4$ & 0.7 & $\mathrm{X}$ & - & -- & --- \\
\hline SP53 & $14.0-21.6$ & 1.0 & $X$ & - & - & $\mathrm{NiFe}$ \\
\hline SP54 & $10.5-12.0$ & 1.5 & $\cdots$ & $m$ & $\mathrm{X}$ & $\cdots$ \\
\hline SP55 & $6.5-14.5$ & 1.0 & $\mathrm{X}$ & - & - & $\cdots$ \\
\hline SP56 & $7.9-10.7$ & 2.0 & $\mathrm{X}$ & - & $\ldots$ & $\mathrm{NiFe}$ \\
\hline SP58 & $3.7-11.2$ & 1.0 & $\mathrm{X}$ & - & - & Fe-sil \\
\hline SP60 & $9.5-12.1$ & 0.7 & $\mathrm{X}$ & $-\infty$ & -- & $\mathrm{NiFe}$ \\
\hline SP63 & $16.1-18.8$ & 3.6 & -.. & - & $\mathrm{X}$ & --- \\
\hline SP64 & $4.6-12.3$ & $2.7-4.2$ & $\mathrm{X}$ & - & $x$ & -- \\
\hline SP66 & $5.2-9.5$ & 0.8 & $\mathrm{X}$ & - & - & An \\
\hline SP69 & $11.5-16.3$ & 4.7 & -- & - & $\mathrm{X}$ & -- \\
\hline SP70 & $19.2-24.2$ & 5.0 & $X$ & $\mathrm{X}$ & - & Fe-sil \\
\hline SP71 & $6.7-12.1$ & 0.9 & $\mathrm{X}$ & $\mathrm{X}$ & - & Fe-sil \\
\hline SP72 & $14.9-27.8$ & $1.6-2.1$ & --- & $\mathrm{x}$ & -- & Fe-sil \\
\hline SI & 14 & $4.3-5.5$ & $\mathrm{X}$ & - & - & $\mathrm{Fe}$-sil \\
\hline SP75 & $20.6-23.0$ & 4.9 & $\mathrm{X}$ & -. & -- & Fe-sil \\
\hline SP77 & $3.9-6.3$ & 0.6 & $\ldots$ & - & - & $\mathrm{Fe}-\mathrm{sil}$ \\
\hline SP78 & $20.1-22.5$ & $4.4-4.9$ & $\cdots$ & - & - & Fe-sil \\
\hline SP79 & $20.6-23.7$ & $4.8-5.3$ & $\mathrm{X}$ & $x$ & - & Fe-sil, E \\
\hline SP80 & $25.8-28.8$ & 8.5 & $\ldots$ & $\cdots$ & -. & $\cdots$ \\
\hline SP81 & $7.3-11.6$ & 2.9 & $\mathrm{X}$ & -. & -.. & Ca-sil \\
\hline \multicolumn{7}{|c|}{ Homogeneous } \\
\hline$S P 21$ & $6.0-7.0$ & 0.8 & --- & - & -- & $\cdots$ \\
\hline SP29 & $8-10$ & 1.5 & -- & - & - & $\cdots$ \\
\hline SP33 & 3 & 0.25 & $\cdots$ & - & $\cdots$ & -- \\
\hline SP36 & $1.5-2.0$ & 0.5 & --- & - & -- & --- \\
\hline SP47 & $14.5 \cdot 15.7$ & 5.5 & --- & -- & -- & -- \\
\hline SP52 & $35.7-36.9$ & $16.0-17.0$ & --- & $\cdots$ & $\ldots$ & $--\cdot$ \\
\hline SP57 & $22.0-23.6$ & 6.7 & $\cdots$ & $\rightarrow$ & - & --- \\
\hline $5 P 59$ & 2.6 & 0.1 & $\cdots$ & - & - & $\mathrm{NiFe}$ \\
\hline SP61 & $16.0 \cdot 16.4$ & 6.0 & $\cdots$ & $x$ & $\cdots$ & $\mathrm{NiFe}$ \\
\hline SP65 & $15.4-15.6$ & 5.7 & --- & $\cdots$ & - & -.. \\
\hline SP68 & $2.7-3.0$ & 0.2 & --- & - & $\cdots$ & Fe-sil \\
\hline SP73 & $3.7-4.3$ & 0.5 & --- & $x$ & --- & Fe-sil \\
\hline \multicolumn{7}{|c|}{ Gradational } \\
\hline SP3 & $14.5-24.2$ & $6.0-7.0$ & $\cdots$ & $\cdots$ & - & - \\
\hline SP27 & $6.1-14.3$ & $2.5-6.0$ & -- & - & - & Ca-sil \\
\hline SP42 & $4.0-5.9$ & 1.0 & $\cdots$ & -- & - & -- \\
\hline SP45 & $2.2-4.3$ & 0.2 & $\cdots$ & -- & - & -- \\
\hline SP48 & $18-20$ & $5.5-6.0$ & $\cdots$ & $\cdots$ & - & Fe-sil \\
\hline \multicolumn{7}{|l|}{ Chevron } \\
\hline SP44 & $0.3-6.0$ & 0.8 & $X$ & --- & $X$ & $\cdots$ \\
\hline SP49 & $16.2-20.2$ & $6.4-7.8$ & - & -- & - & - \\
\hline SP50 & $15.4-21.2$ & 6.0 & $\mathrm{X}$ & $\mathrm{X}$ & - & $\mathrm{NiFe}$ \\
\hline \$P62 & $3.0-7.8$ & 0.7 & $X$ & $x$ & - & $\mathrm{FeS}$ \\
\hline SP67 & $2.0-15.0$ & $3.4-4.4$ & -- & -- & -- & --- \\
\hline SP76 & $1.3-4.7$ & $0.2-0.5$ & $\cdots$ & $\cdots$ & - & Fe-sil \\
\hline \multicolumn{7}{|c|}{ Core-rim } \\
\hline SP5 & $1.2-5.5$ & 0.65 & $\mathrm{X}$ & $\ldots$ &.- & $\mathrm{NiFe}$ \\
\hline SP28 & $1.0-7.0$ & 0.7 & $\mathrm{X}$ & $=$ & - & -- \\
\hline
\end{tabular}

Ranges determined by energy dispersive analysis have fewer significant figures than those determined by wavelength dispersive anaiysis.

An " $\mathrm{X}$ " indicates that the phase is present. Al-diop: aluminous diopside; En: enstatite; An: anorthite; Fe-sil Fe-silicate; Ca-sil: Ca-silicate.

\section{Homogeneous}

Twelve of the fifty-seven grains we studied appear homogeneous, with internal ranges in $\mathrm{Cr}_{2} \mathrm{O}_{3}$ contents $\leq 2 \mathrm{wt} \%$ and no discernible electron albedo differences in high-contrast BEI. These grains typically have no inclusions. 

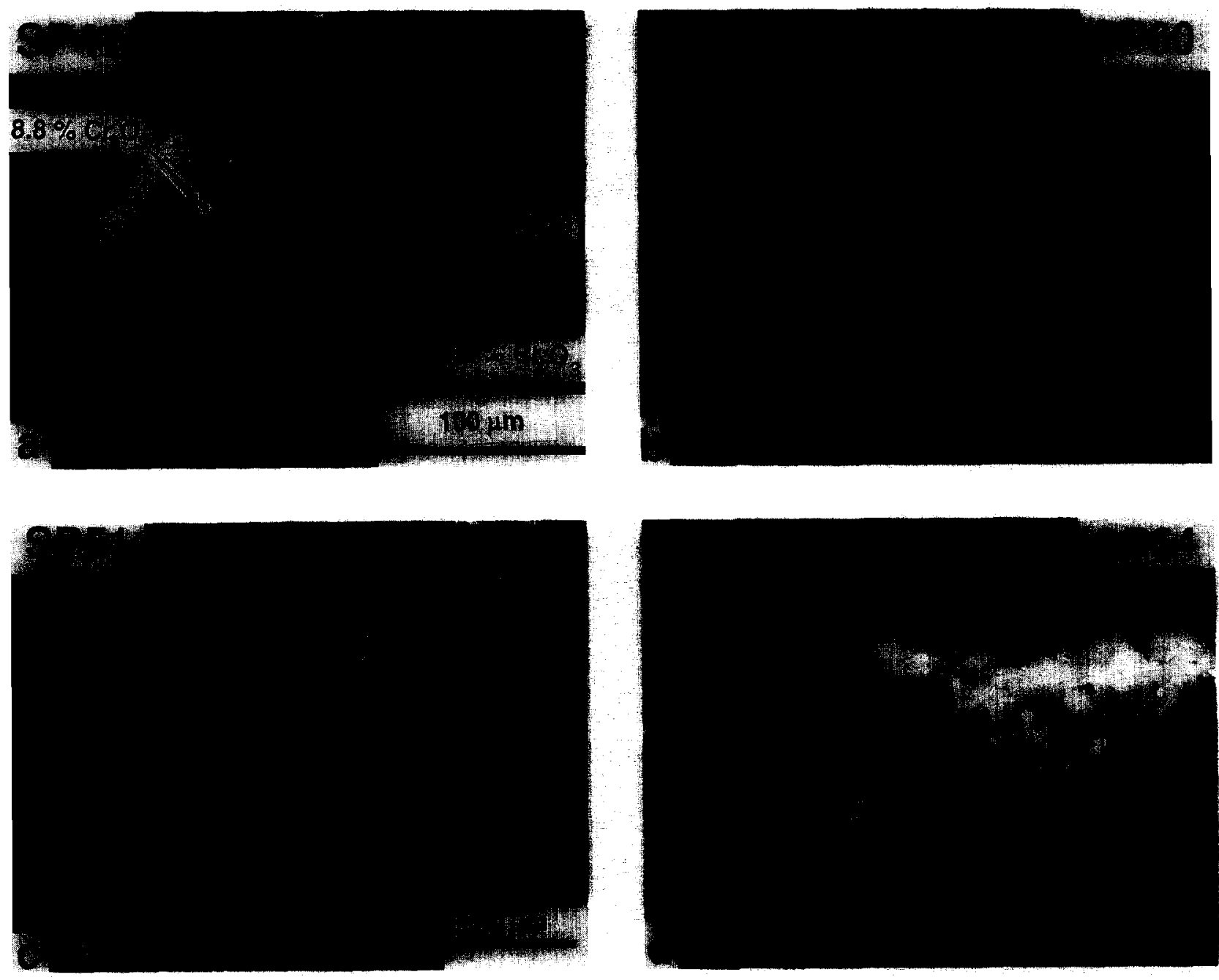

FIG. I. Backscattered electron images ( $\mathrm{BEI}$ ) of spinel grains which represent the various zoning types. Lighter regions within spinel are zones of relatively high $\mathrm{Cr}_{2} \mathrm{O}_{3}$ content. (a) Patchy spinel. Very bright grains within the spincl are inclusions of aluminous diopside. (b) Patchy spinel, with relatively large, regularly shaped patches. (c) Patchy spinel. with diffuse, irregularly shaped patches. (d) Patchy spinel, with Cr-rich patches concentrated in one part of the crystal. (e) Gradational spinel. Cr decreases from upper left to lower right. (f) Chevron spinel. Note the several straight, angular bands of differing $\mathrm{Cr}$ contents, which crystallized around a forsterite grain. In $(\mathrm{f}),(\mathrm{g})$, and $(\mathrm{h})$, solid lines indicate locations of electron probe traverses. ( $\mathrm{g}$ ) Chevron spinel, in which the bands are parallel to crystal faces. ( $\mathrm{h}$ ) Corerim spinel, which has a Cr-poor core and several outer Cr-rich bands parallel to crystal faces. The boundary between the core and the Cr-rich spinel is highly irregular and embayed. Al-diop: Aluminous diopside. Fo ${ }_{x}$ : mole percent forstent: in olivine.

\section{Gradational}

In this type, $\mathrm{Cr}_{2} \mathrm{O}_{3}$ varies fairly smoothly across the grains, by as much as $10 \mathrm{wt} \%$. An example is shown in Fig. le. Because these are crystal fragments, and the zoning is not concentric, we cannot be certain that straight edges are crystal faces. If we assume they are, then we can infer core-rim relationships. It appears that in three of the grains, $\mathrm{Cr}_{2} \mathrm{O}_{3}$ increases toward the rim of the crystal and, in two others, it decreases. In sample SP27, FeO covaries with $\mathrm{Cr}_{2} \mathrm{O}_{3}$ and ranges from 2.5 to $6 \mathrm{wt} \%$.

\section{Chevron}

Six samples fall into this category, in which the grains have as many as ten angular, concentric, sharply defined bands with differing $\mathrm{Cr}_{2} \mathrm{O}_{3}$ contents (Fig. I f.g). In this type and the core-rim type (see below), there is concentric zoning, so we can identify the cores and rims of crystals with more confidence than we can for the gradational grains. In at least two cases, including the sample shown in Fig. $1 \mathrm{~g}$, the layers are parallel to crystal faces. Band widths range from $\sim 5$ to $\sim 30$ $\mu \mathrm{m}$, with typical composition differences of $2-3 \mathrm{wt} \% \mathrm{Cr}_{2} \mathrm{O}_{3}$. One sample, SP44, has a core with $\sim 5 \mathrm{wt} \% \mathrm{Cr}_{2} \mathrm{O}_{3}$, a low$\mathrm{Cr}_{2} \mathrm{O}_{3}$ zone $(0.4 \mathrm{wt} \%)$, and an outermost layer with $\sim 4 \mathrm{wt} \%$. In four other chevron-type grains, the core is relatively low in $\mathrm{Cr}_{2} \mathrm{O}_{3}$, the layer adjacent to it is the most $\mathrm{Cr}_{2} \mathrm{O}_{3}$-rich one. and outward from this layer are alternating bands of high and low $\mathrm{Cr}_{2} \mathrm{O}_{3}$ contents superimposed on a general trend of decreasing $\mathrm{Cr}_{2} \mathrm{O}_{3}$.

\section{Core-rim}

The two grains of this type have low- $\mathrm{Cr}_{2} \mathrm{O}_{3}(1-2 \mathrm{wt} \%)$ cores completely enclosed by high- $\mathrm{Cr}_{2} \mathrm{O}_{3}(5-6 \mathrm{wt} \%)$ rims. 

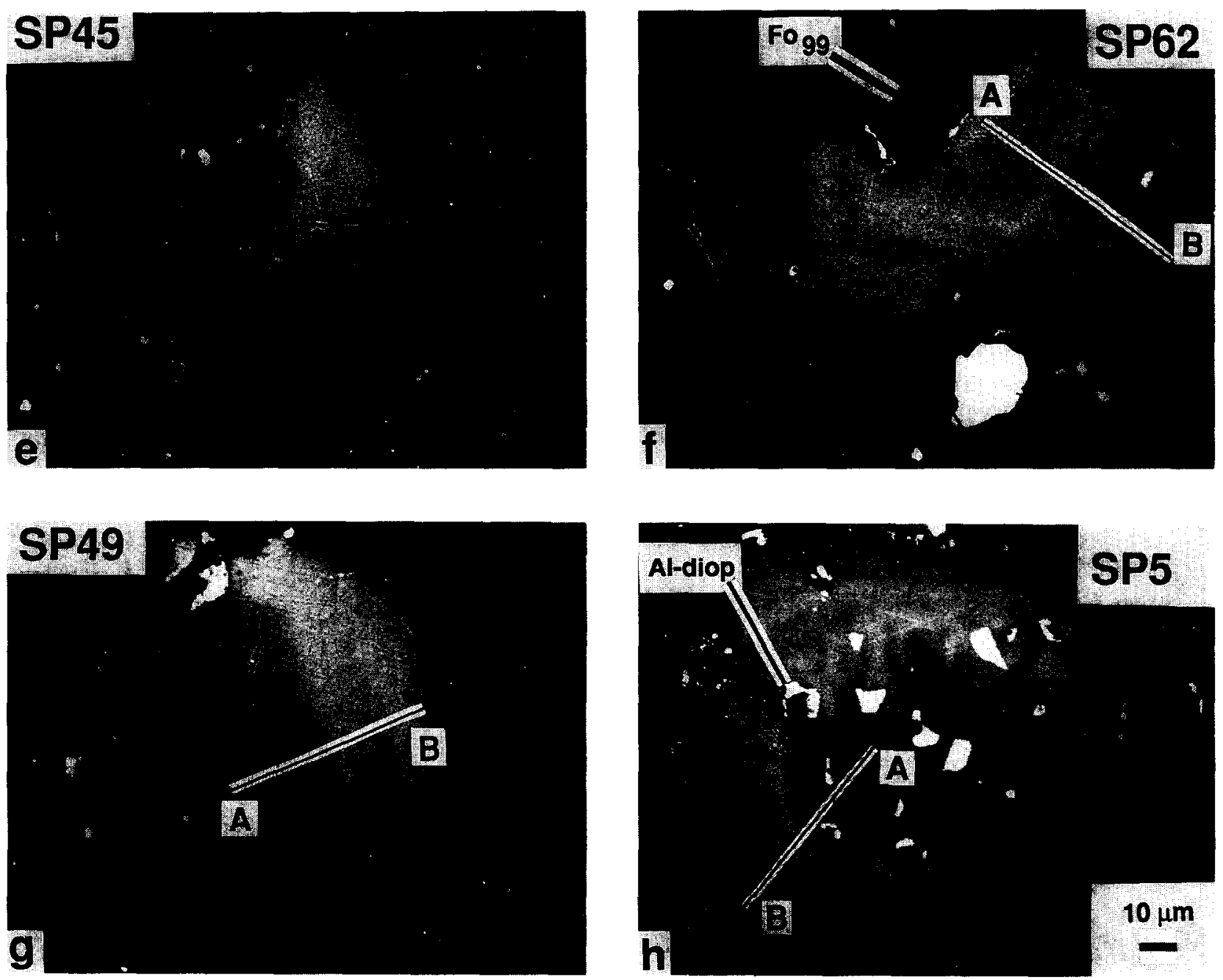

FIG. 1. (Continued)

and, unlike the chevron-type grains, the boundaries between the two zones are irregular and embayed, as in SP5 (Fig. Ih). Like some chevron-type grains, the mantle of SP5 has thin layers of alternating ( high and low ) $\mathrm{Cr}_{2} \mathrm{O}_{3}$ contents. The other core-rim sample, SP28, does not have discrete layers in its rim.

\section{In-situ Spinel}

Because the freeze-thaw process may have separated most of the spinel grains from any coexisting phases, we have searched optically for occurrences of analogous spinels in their original setting in a total of $\sim 8 \times 10^{3} \mathrm{~mm}^{2}$ in 40 Murchison thin sections, eight of which were examined in detail by SEM. Despite the large number of spinel grains obtained by freeze-thaw disaggregation, this exhaustive search of thin sections revealed only two grains which fall within both the size and composition ranges of the separated spinel grains. Taking into consideration the mass disaggregated (50-200 g; MacPHerson et al., 1980), the number of spinel grains recovered $(\sim 100)$, and the relatively small mass sampled by a thin section ( $17 \mathrm{mg}$ ), we estimate that there should be $0.3-$ 1.4 spinel grains ( $100 \mu \mathrm{m}$ across) per 40 thin sections, roughly consistent with the number we found.
One spinel-bearing inclusion, in section $\mathrm{M} 1$, consists of an $\sim 250 \times 100 \mu \mathrm{m}$. patchy, pale pink spinel enclosed on three sides by anhedral olivine and an Fe-rich alteration product (Fig. 2a). Onc of the olivine-spinel contacts is straight but the other two are curved, with the spinel concave relative to the olivine. The remaining edge is in contact with the matrix of the meteorite. The spinel has inclusions of olivine, aluminous diopside and the Fe-rich alteration product. The olivine contains (r-bearing. aluminous diopside inclusions up to $\sim 10 \mu \mathrm{m}$ across.

The other occurrence of a large spinel in an inclusion, in section $4377-1$ (Fig. 2b), is similar to that in M1, consisting predominantly of coarse, pale pink spinel and anhedral olivine, with the spinel partially enclosing an adjacent olivine crystal. Also, as in Ml, there is an Fe-rich alteration product adjacent to both the olivine and spinel. In some places, it appears to have replaced whole lath-shaped crystals. In 4377 1 , however, the spinel is homogenenus ( $n$ nt patchy as in M1); the inclusion in 4377-1 contains exsolved high- and low-Ca pyroxene; and the olivine contains inclusions of Ca-rich pyroxene and stringers and isolated blebs of Fe metal in a texture similar to that observed in ureilites (NFuJVONEN et al., 1972). There is also Ca rich pyroxene adjacent to some of the metal blebs. The spinel and olivine grains are $\sim 100 \mu \mathrm{m}$ across but 

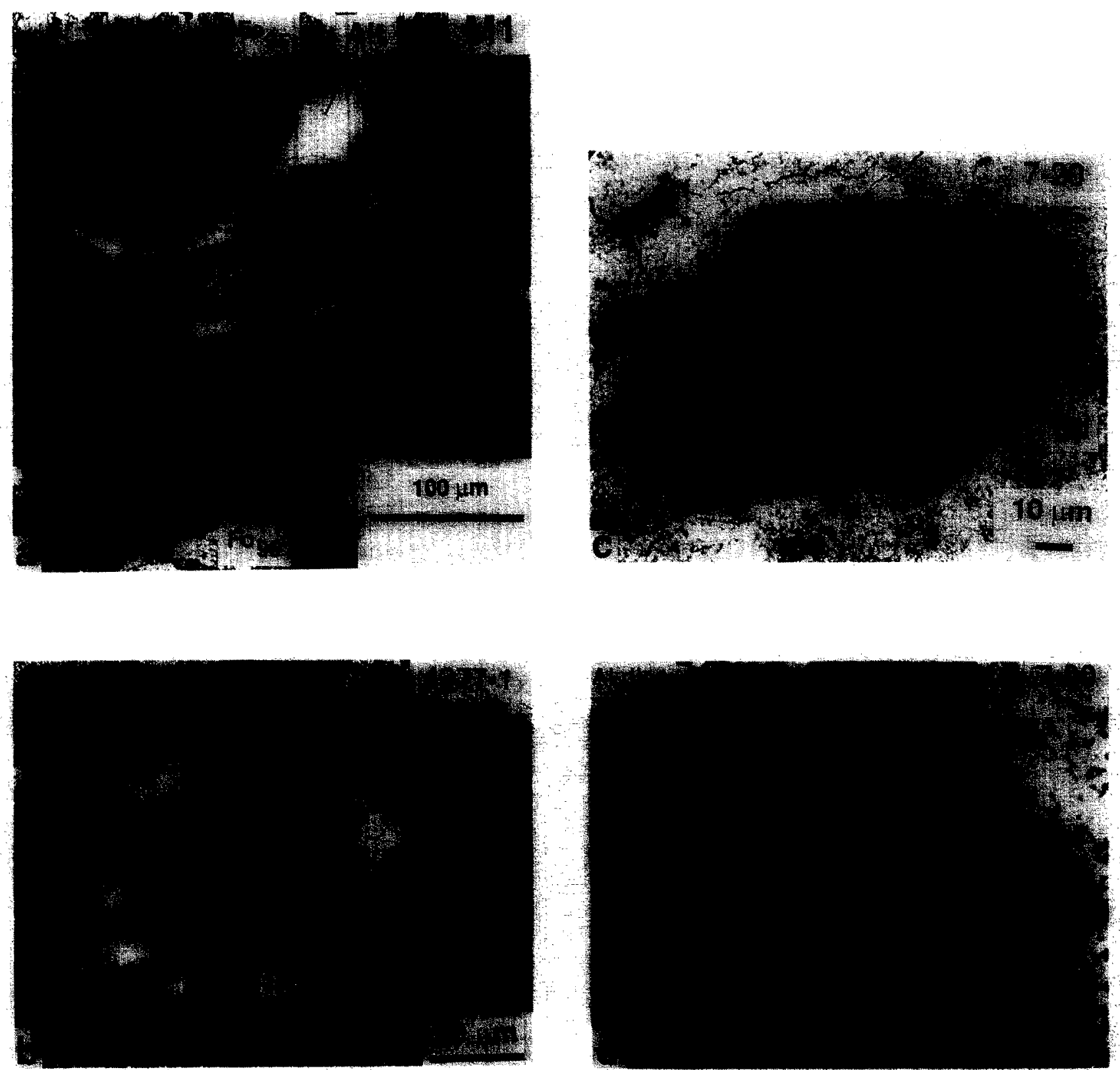

FIC. 2. BEI of in situ spinel. (a) Patchy spinel, partially enclosing olivine grains. (b) Homogeneous spinel, again partially enclosing olivine. (c) Patchy spinel between several olivine grains. (d) Higher-magnification and highercontrast view of patchy spinel in $2(\mathrm{~b})$. As in Ml, there is no obvious relationship between the spinel-matrix contact and the pattern of patches. (c) Chondrule with olivine and homogeneous, gradational and core-rim spinel in a matrix of aluminous diopside. Most of the olivine nucleated on the edge and grew inward. (f) Chondrule with subhedral to euhedral olivine and homogeneous spinel in a matrix of aluminous diopside. Sp; spinel; $\mathrm{cpx}$ : clinopyroxene; Ol: olivine: Aldiop: aluminous diopside: Phy: phyllosilicate: Alt: alteration product: $\mathrm{Fo}_{x}$ : mole percent forsterite in olivine.

the pyroxene is much finer $(<20 \mu \mathrm{m})$. Neither $\mathrm{Ml}$ nor 4377 $I$ is round, and they probably are fragments of once-larger objects.

In addition to $\mathrm{M} 1$, the only other patchy spinel grain which we have found in a thin section of Murchison is a small, 30 $\times 20 \mu \mathrm{m}$ grain in sample $7-20$ (Fig. $2 \mathrm{c}, \mathrm{d}$ ). As in the in-situ occurrences previously described, the spinel wraps around rounded olivine crystals. In this sample, the spinel is also adjacent to a subhedral olivine crystal that is $\sim 100 \times 85 \mu \mathrm{m}$ and whose contact with the spinel is also curved, but along part of the boundary the olivine curves around the spinel. Aluminous diopside is present between the two smaller olivine crystals and as inclusions in the spinel. The large olivine crystal contains $\mu \mathrm{m}$-sized blebs of Fe metal. In this sample, as in M1, the patchy spinel is in contact with the matrix of the meteorite, but there is no relationship between these contacts and the patches.

In our density separates, we found a chondrule, M92SPI, $200 \mu \mathrm{m}$ in diameter, consisting of anhedral to subhedral $\mathrm{Cr}$ bearing spinel ( $20-50 \mu \mathrm{m}$ across) and anhedral to euhedral 

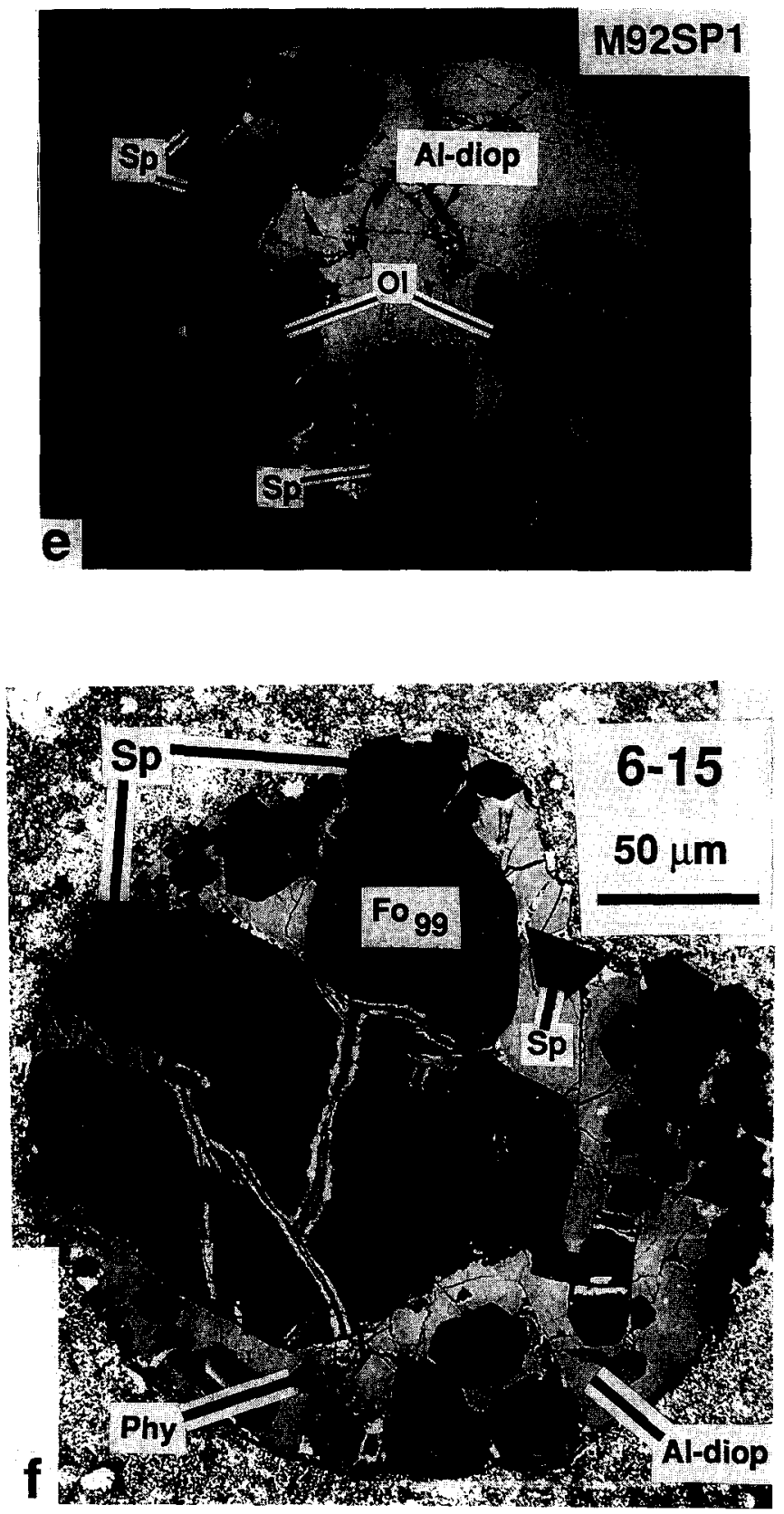

FIG. 2. (Continued)

olivine (30-75 $\mu \mathrm{m}$ long) in a matrix of aluminous diopside (Fig. 2e) Several grains of aluminous diopside are present, the largest being $75 \mu \mathrm{m}$ across. Most spinel and olivine crystals are at or near the rim, including one spinel grain (at left in Fig. 2e) that has crystallized around olivine, and the olivine grains are oriented at high angles to the surface of the chondrule. Onc of the spinel grains is homogeneous; two are $\mathrm{Cr}$ and Fe-rich at the surface of the chondrule, becoming less so inward, and are classified as gradational; and two others (at bottom center of Fig. 2e), which have grown together, have low- $\mathrm{Cr}$ cores and relatively $\mathrm{Cr}$-rich rims, with smooth boundaries between the zones.

The mineralogy of this chondrule is very similar to one found in thin section, sample 6-15 (Fig. 2f). This sample also contains olivine and spinel in a matrix of aluminous diopside. In addition, it contains phyllosilicate and FeS, and has a higher olivine/pyroxene ratio than M92SP1. The olivine, $F_{99}$, is coarse $(25-150 \mu \mathrm{m})$ and subhedral to euhedral. Spinel occurs as small, homogeneous grains $\sim 20 \mu \mathrm{m}$ across, and is also subhedral to euhedral. In one place (at left in Fig. 2f), as in M92SP1, it has crystallized around the end of an olivine crystal, indicating that spinel crystallized after olivine.

\section{Inclusions in Spinel}

In addition to their relatively large sizes and various zoning patterns, another distinctive feature of the separated spinel grains is their inclusions. As indicated in Table 1, the most common inclusion by far is aluminous diopside (12-24 wt\% $\mathrm{Al}_{2} \mathrm{O}_{3}$ ), which occurs in twenty-six grains. Of these, twentyone have patchy zoning, three have chevron zoning, and two are core-rim grains. The diopside inclusions are anhedral, typically $2-10 \mu \mathrm{m}$ across and, in many cases. are associated with circular voids, as if pre-existing cavities were partially filled by diopside. There are several exceptions to this mode of occurrence. One grain, SP6, has a $25 \mu \mathrm{m}$-thick rind of aluminous diopside which partially encloses both the spinel and an adjacent forsterite grain. Sample SP23 has an irregularly shaped, $\sim 50 \mu \mathrm{m}$ inclusion, and SP4 has a very thin, discontinuous layer of aluminous diopside between forsterite and the spinel that partially encloses it.

Eleven spinels (seven patchy, two chevron, two homogeneous) occur with olivine, and in all but two of them, SP6 and SP71, spinel partially to completely encloses the olivine, providing clear textural evidence that, in those nine samples, olivine formed before spinel. An example is SP62. shown in Fig. 1f. In six cases (SP4, SP6, SP23, SP62, SP73, and SP79), the olivine is pure forsterite, in one (SP72) it is $\mathrm{Fo}_{97-98}$ and in four others (SP50, SP61, SP70, and SP71), it is Fo95-96. The olivine ranges in size from 10 (SP7 1 ) to $\sim 100 \mu \mathrm{m}$ (SP50 and SP70) and in shape from anhedral (SP4, SP23, SP50, SP61, SP71, and SP79) through subhedral (SP62, SP70, SP72, and SP73) to nearly euhedral (SP6). In SP50 and SP61, the olivine contains micrometer-sized blebs of NiFe metal. The olivine in SP50 also has several anhedral. $\sim 5 \mu \mathrm{m}$ inclusions of Cr-spinel.

Five spinel grains have 5-10 $\mu \mathrm{m}$-sized inclusions of $\mathrm{Ca}$-, Al-. Si-rich glass. Somc are shown in Fig. 3. These glass inclusions tend to be relatively angular, unlike those found in olivine crystals in Murchison (FUCHS et al., 1973; ROEDDER, 1981 ). Sample SP64 is unusual in that it has a two-phase inclusion consisting of aluminous diopside and glass. Of the five spinels with glass, four have patchy zoning and one has chevron zoning.

Other inclusions observed in spinel are Fe-silicate (probably an alteration product), FeS, FeNi metal, and, in SP66, $\sim 10$ $\mu \mathrm{m}$ grains of anorthite or glass of anorthite composition. SP7, SP27, and SP81 contain grains of a Ca-silicate that are too small to identify.

\section{PHASE COMPOSITIONS}

\section{Spinel}

The suite of separated spinel grains exhibits a wide range of $\mathrm{Cr}_{2} \mathrm{O}_{3}(0.3-37 \mathrm{wt} \%)$ and $\mathrm{FeO}(0.2-17 \mathrm{wt} \%)$ contents. 


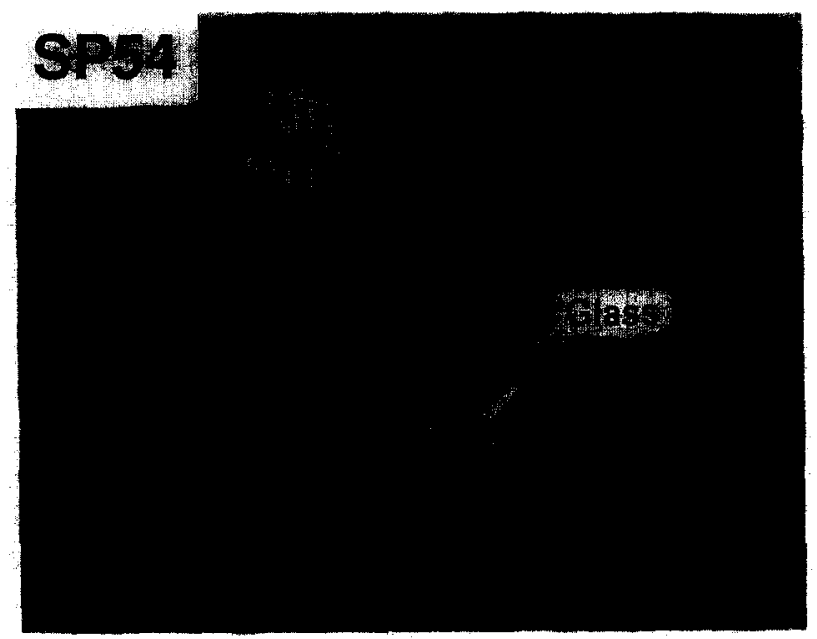

Fici. 3. Glass inclusions in SP54. Vote thedr angular shapes. whith are unlike the rounded inclusions found in olivine. Scale har is 10 $\mu m$.

Representative analyses are given in 1 able 2. So litlle $\mathrm{TiO}_{2}$ is present in the spinel that compositions can be represented by $(\mathrm{Mg}, \mathrm{Fe})(\mathrm{Al}, \mathrm{Cr})_{2} \mathrm{O}_{4}$ and plotted on the base of the multicomponent spinel prism (e.g., HAGGERTY, 1972). Because many individual crystals have variations in $\mathrm{Cr}_{2} \mathrm{O}_{2}$ contents but virtually none in $\mathrm{FeO}$, the effective substitutions are simply Fe for $\mathrm{Mg}$ and $\mathrm{Cr}$ for $\mathrm{Al}$, and not FeCr for MgAl. Nearly perfect anticorrelations between $\mathrm{Mg}$ and Fe and between $\mathrm{Cr}$ and $\mathrm{Al}$ (Fig. 4) are observed, illustrating the dominance of these substitutions over others. such as $\mathrm{Cr}$ for $\mathrm{Mg}$.

$\mathrm{V}_{2} \mathrm{O}_{3}$ ranges from 0.01 to $0.4 \mathrm{wt} ;$ and is positively correlated with $\mathrm{Cr}_{2} \mathrm{O}_{3}$ contents $(r=0.72)$, which is understandable because both elements are compatible in normal spinel (IRVING. 1978). $\mathrm{TiO}_{2}$ contents are typically $0.2-0.4 \mathrm{wt} \%$ and are also correlated with $\mathrm{Cr}_{2} \mathrm{O}_{3}$ contents. but not as strongly
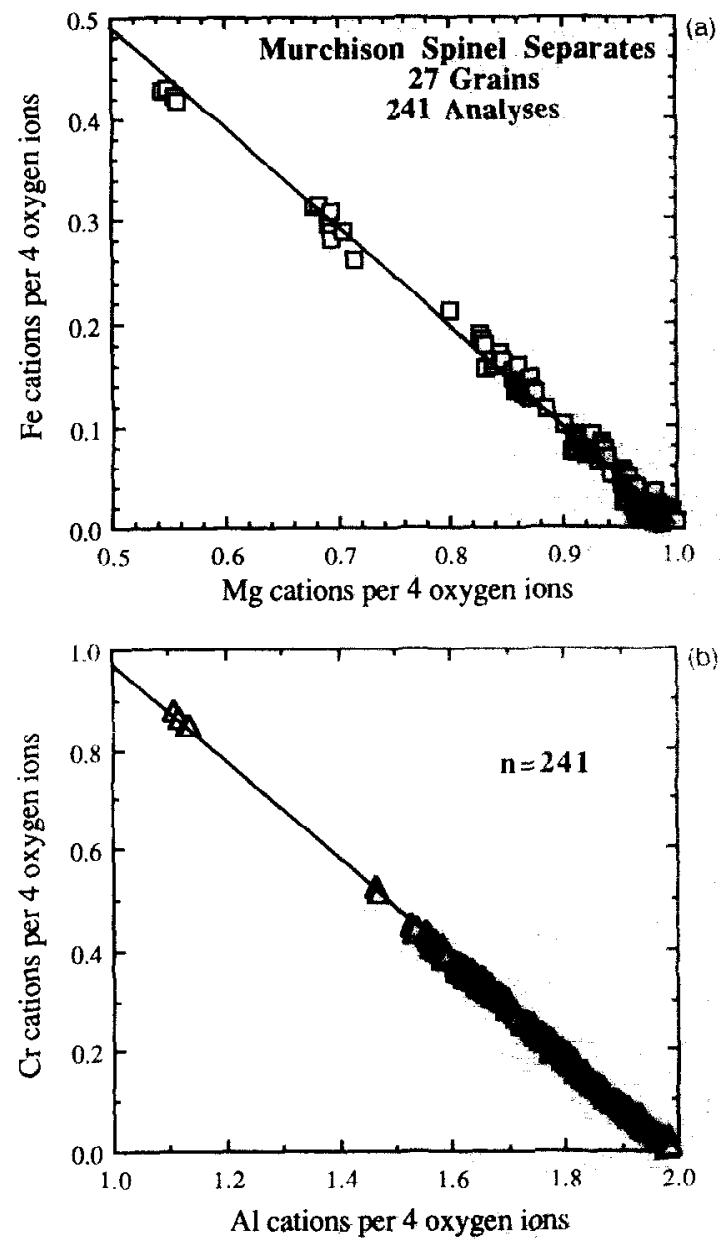

Fig. 4. Summary of Fe-Mg (a) and $\mathrm{Cr}-\mathrm{Al}$ (b) relationships in electron microprobe analyses of spinel. The best fit lines through the data have slopes very close to -1 , showing that these are the dominant substitutions in these spinels.

Table 2. Representative analyses of spinel.

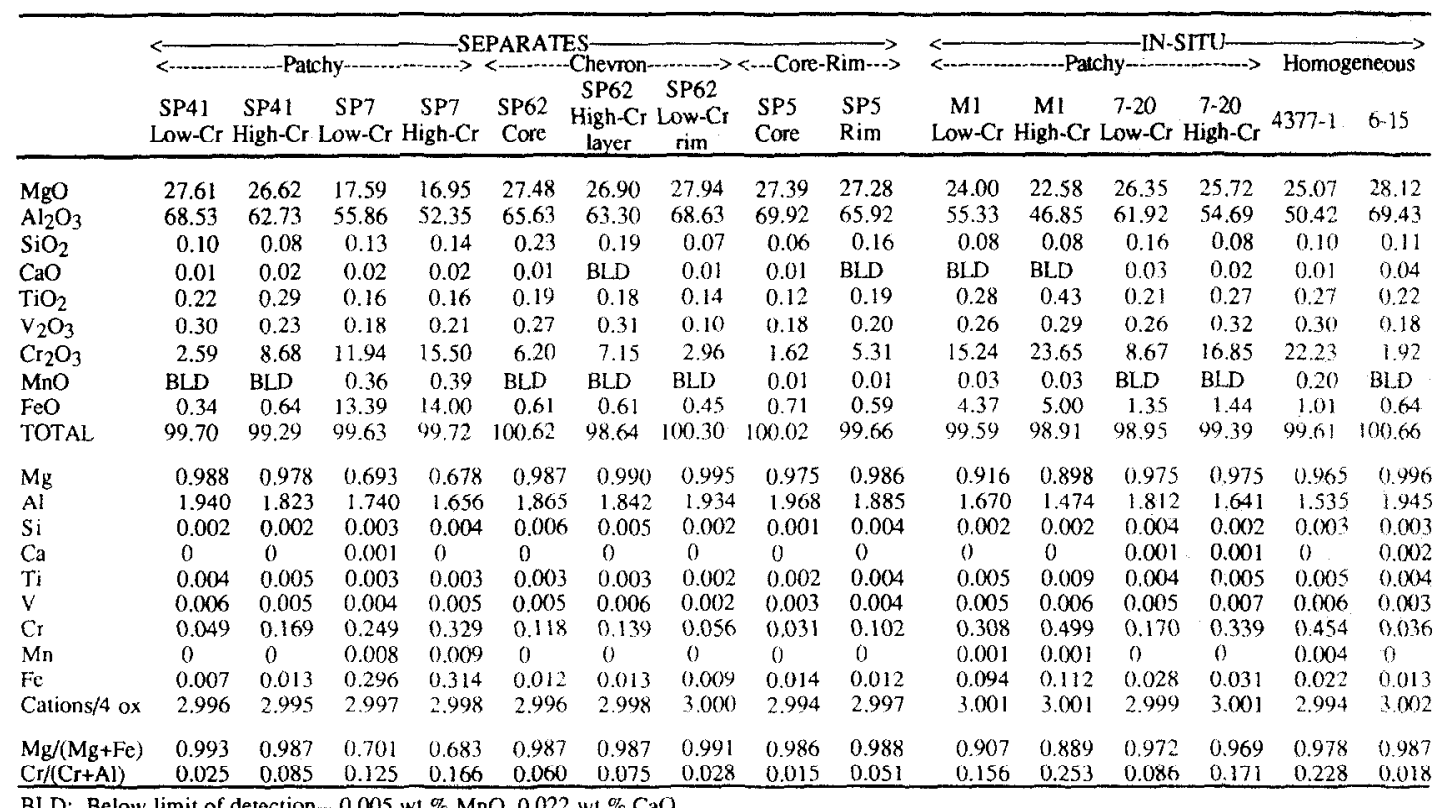

BLD: Below limit of detection -0.005 wt \% $\mathrm{MnO} 0.022$ w1 \% $\mathrm{CaO}$. 

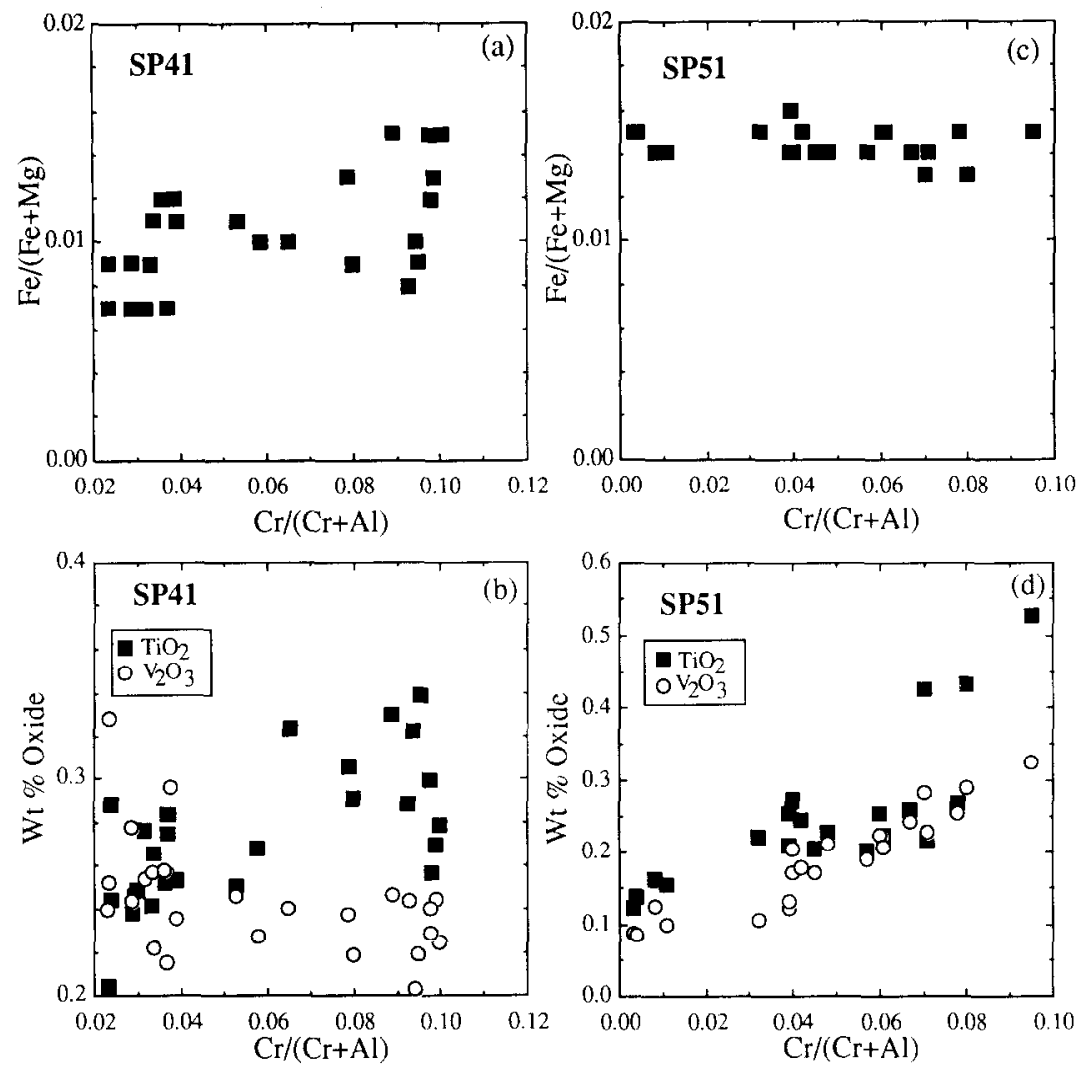

FiG. 5. Plots of atomic $\mathrm{Fe} /(\mathrm{Fe}+\mathrm{Mg})$ and $\mathrm{wt} \% \mathrm{TiO}_{2}$ and $\mathrm{V}_{2} \mathrm{O}_{3}$ vs. atomic $\mathrm{Cr} /(\mathrm{Cr}+\mathrm{Al})$ ratios in two patchy spinel grains. (a. b) SP41. (c, d) SP51.

as $\mathrm{V}_{2} \mathrm{O}_{3}$ is. $\mathrm{MnO}$ contents are $<0.2 \mathrm{wt} \%$ in most spinels, but are $\sim 0.4-0.8 \mathrm{wt} \%$ in the two spinels (SP7 and SP52) with $>10 \mathrm{wt} \%$ FeO. In two other samples, SP49 and SP56, MnO contents are positively correlated with $\mathrm{FeO}$ contents. $\mathrm{ZnO}$ contents are low $(<0.015 \mathrm{wt} \%)$ in all samples.

Tables 1 and 2 show that the compositions of the low-Cr and high-Cr patches in the patchy spinels vary from grain to grain. While the $\mathrm{FeO}$ contents are typically uniform from patch to patch within individual grains, the observed maximum differences in $\mathrm{Cr}_{2} \mathrm{O}_{3}$ concentrations between patches range from 1.5 to $12.9 \mathrm{wt} \%$ from grain to grain, and average $4.7 \mathrm{wt} \%$. Analyses of the patchy spinels SP41 (Fig. la) and SP51 (Fig. 1C) are shown in Fig. 5. In both spinels $\mathrm{Cr} /(\mathrm{Cr}$ $+\mathrm{Al}$ ) (henceforth $\mathrm{Cr} \#$ ) ranges from $\leq 0.02$ to $\sim 0.10$ but $\mathrm{Fe} /$ ( $\mathrm{Fe}+\mathrm{Mg}$ ) (henceforth $\mathrm{Fe \#}$ ) has a much narrower range. In SP41, in which most of the contacts between patches are sharp, the $\mathrm{Cr} \#$ varies continuously, showing no hiatus $>0.014$. In SP51, in which the contacts are diffuse, a hiatus in $\mathrm{Cr} \#$ of 0.021 is seen. In SP41 the Cr-rich patches tend to be higher in $\mathrm{TiO}_{2}$ and lower in $\mathrm{V}_{2} \mathrm{O}_{3}$ than the low-Cr patches, but there is much overlap between patches in the contents of these oxides. In the patches in SP51, $\mathrm{TiO}_{2}$ and $\mathrm{V}_{2} \mathrm{O}_{3}$ contents are positively correlated with $\mathrm{Cr}$, unlike SP41.

Although individual homogeneous spinel grains have uniform compositions, taken as a group, the homogeneous spinels have a very wide range of $\mathrm{Cr}_{2} \mathrm{O}_{3}$ contents, from 1.5 to 37 wt $\%$ (Table 1). The grain with the most $\mathrm{Cr}_{2} \mathrm{O}_{3}$, SP52, also has the highest $\mathrm{FeO}$. Individual gradational grains have variations in $\mathrm{Cr}_{2} \mathrm{O}_{3}$ of up to $10 \mathrm{wt} \%$, and in two of the samples, SP27 and SP42, Fe\# covaries with $\mathrm{Cr} \#$, as shown in Fig. 6.

Data from electron probe traverses on the chevron grains shown in Fig. 1 are given in Fig. 7. The data for SP62 show that the bands visible in the BEIs (Fig. If) are due to variations in $\mathrm{Cr} \#$; the Fe\# is virtually constant across the grain. In this sample and SP67 (not shown), the outermost layer is very $\mathrm{Cr}$-poor, and $\mathrm{TiO}_{2}$ and $\mathrm{V}_{2} \mathrm{O}_{3}$ also drop off sharply. SP49 has

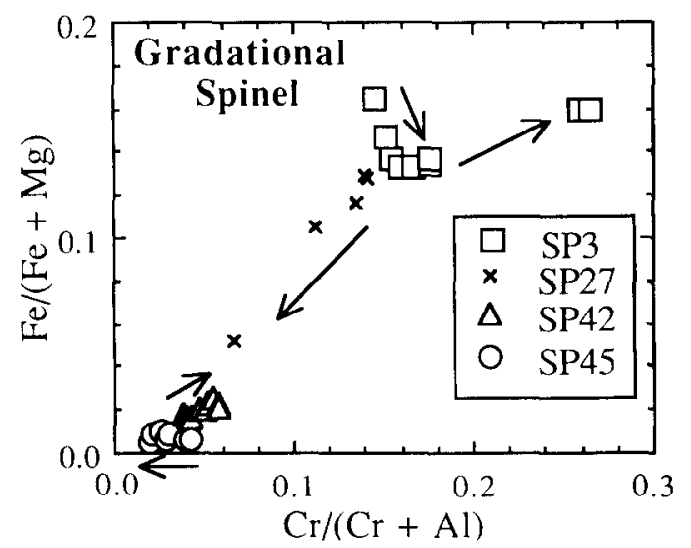

$\mathrm{FlG}$. 6. Plot of atomic $\mathrm{Fe} /(\mathrm{Fe}+\mathrm{Mg})$ vs. atomic $\mathrm{Cr} /(\mathrm{Cr}+\Lambda \mathrm{l})$ ratios in gradational spinel grains. Arrows point away from the core composition toward the rim composition for each grain. The ratios arc correlated in this group overall and within SP42 and SP27. 

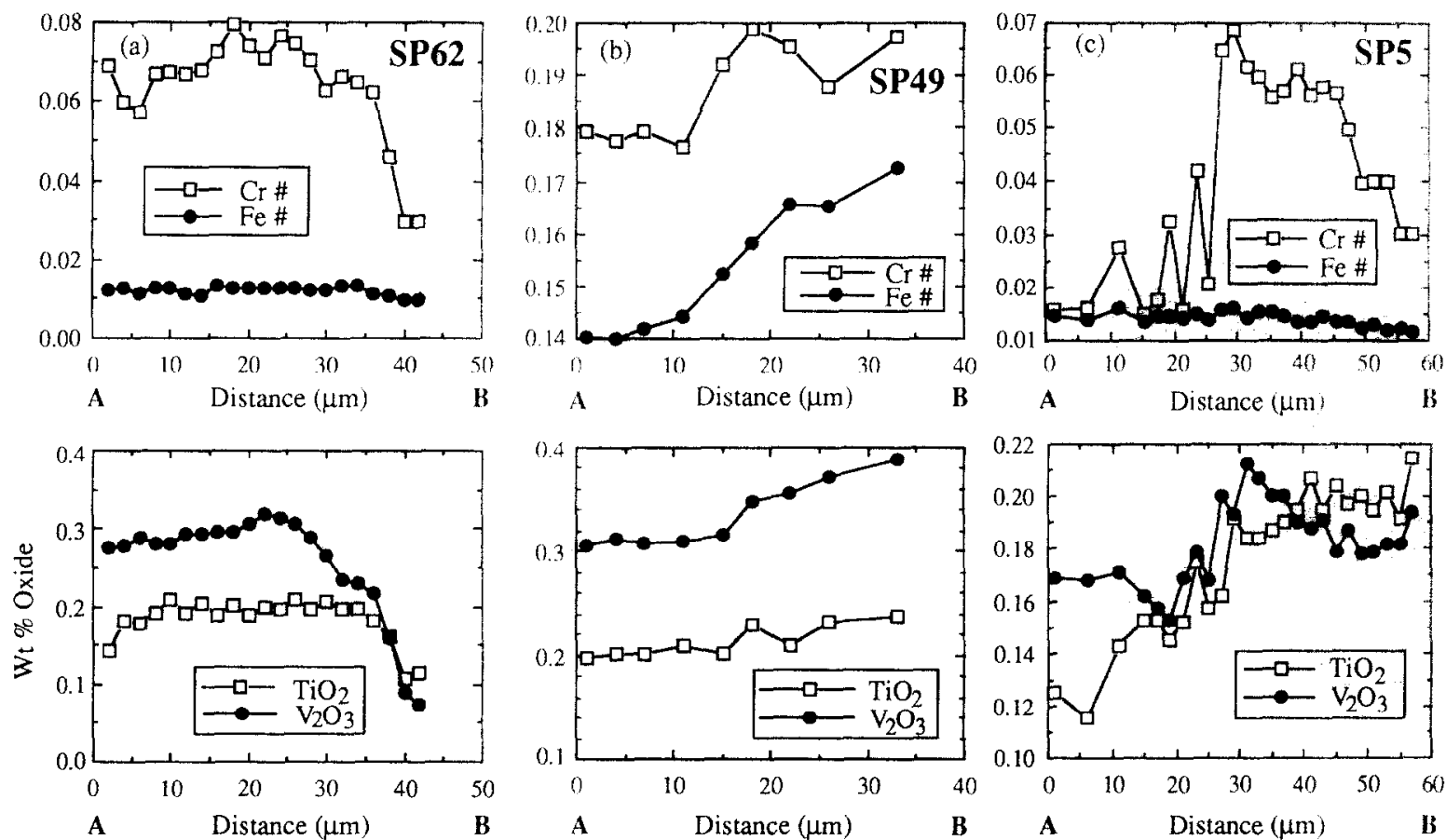

FIG. 7. Results of electron probe traverses for the chevron and core-rin grains shown in Fig. 1, "A" and "B" correspond to the end points of each traverse and are also indicated in Fig. $1 . \mathrm{Cr} \#=$ atomic $\mathrm{Cr} /(\mathrm{Cr}+\mathrm{Al})$; Fe\# $=$ atomic $\mathrm{Fe} /(\mathrm{Fe}+\mathrm{Mg})$. (a) SP62, chevron type. Note uniformity of $\mathrm{Fe} /(\mathrm{Fe}+\mathrm{Mg})$ ratio despite variations in Cr $\#$. (b) SP49, chevron type. $\mathrm{Fe} /(\mathrm{Fe}+\mathrm{Mg})$ increases from core to rim, while $\mathrm{Cr} /(\mathrm{Cr}+\mathrm{Al})$ increases, decreases, then increases again. (c) SP5, core-rim type. The data reflect a $\mathrm{Cr}$-poor core enclosed by alternating $\mathrm{Cr}$-rich and $\mathrm{Cr}$-poor layers. Note the high $\mathrm{V}_{2} \mathrm{O}_{3} / \mathrm{TiO}_{2}$ ratio of the core $(0-20 \mu \mathrm{m})$ relative to the outer parts of the crystal.

a uniform, low-Cr core and relatively $\mathrm{Cr}_{2} \mathrm{O}_{3-}, \mathrm{FeO}-$, and $\mathrm{V}_{2} \mathrm{O}_{3^{-}}$ rich outer layers. Three layers (light, dark, and light) can be seen in Fig. 1g, and the data from the traverse also show a relatively $\mathrm{Cr}$-poor core ( 0 to $\sim 10 \mu \mathrm{m}$ ) followed by a relatively $\mathrm{Cr}$-rich layer, a relatively $\mathrm{Cr}$-poor one, and another $\mathrm{Cr}$-rich one. This grain is unusual in that $\mathrm{FeO}$ increases from core to rim, whereas most other spinels in this suite have uniform FeO contents. In the data for SP5 (core-rim type), note that the Fe\# is $\leq 0.015$ throughout the traverse despite the fluctuations in $\mathrm{Cr} \#$, which again correspond to layers visible in the $\mathrm{BEI}$ ( Fig. $\mathrm{lh}$ ). The core has a much higher $\mathrm{V}_{2} \mathrm{O}_{3} / \mathrm{TiO}_{2}$ ratio than the outer layers.

Among the in-situ samples, the patchy spinel in $\mathrm{M} 1$ is $\mathrm{Cr}$ rich, with 15-23 wt $\% \mathrm{Cr}_{2} \mathrm{O}_{3}$, and it has 4.5-5 wt $\% \mathrm{FeO}$. FeO and $\mathrm{V}_{2} \mathrm{O}_{3}$ are positively correlated with $\mathrm{Cr}_{2} \mathrm{O}_{3}$. In 7-20, FeO, $\mathrm{TiO}_{2}$, and $\mathrm{V}_{2} \mathrm{O}_{3}$ are all positively correlated with $\mathrm{Cr}_{2} \mathrm{O}_{3}$. In chondrule 6-15, the spinel is homogeneous, with 1.9-2.2 wt\% $\mathrm{Cr}_{2} \mathrm{O}_{3}$ and 0.6-0.7 wt\% FeO. Spinel in chondrule M92SP1 has 4.5-7.7 wt $\% \mathrm{Cr}_{2} \mathrm{O}_{3}$ and $1.1-2.1 \mathrm{wt} \% \mathrm{FeO}$.

\section{Pyroxene}

Representative analyses are given in Table 3. Pyroxenc associated with the separated spinels is aluminous diopside, with at least $11 \mathrm{wt} \% \mathrm{Al}_{2} \mathrm{O}_{3}$ and up to $3.7 \% \mathrm{TiO}_{2} . \mathrm{MgO}, \mathrm{Al}_{2} \mathrm{O}_{3}$, and $\mathrm{TiO}_{2}$ contents are within the ranges for low-Ti pyroxene from refractory inclusions ( $\mathrm{Ca}-, \mathrm{Al}$-rich inclusions, or CAIs) in Murchison (MACPHERSON et al., 1983, 1984a), although some of the latter have pyroxene containing higher $\mathrm{TiO}_{2}$ and $\mathrm{Al}_{2} \mathrm{O}_{3}$, as does fassaite from Allende Type B CAIs. In SP6,

pyroxene forms a partial rind of uniform composition around the spinel. In the other sample (SP23) with pyroxene coarse enough to permit more than one analysis per grain, the pyroxene is also uniform in composition. Almost all pyroxene in the separated spinels has $<1 \mathrm{wt} \% \mathrm{FeO}$, with the exception of that in SP7. In this sample, spincl has -14 wt $\%$ FeO and pyroxene has $6-8 \mathrm{wt} \%$.

Table 3. Compositions of pyroxene enclosed in spinel or occurring in spinel-bearing assemblages.

\begin{tabular}{|c|c|c|c|c|c|c|c|c|c|c|}
\hline & SP5 & SP6 & SP7 & SP23 & SP41 & SP51 & SP53 & $4377-1$ & $7-20$ & $0-15$ \\
\hline $\mathrm{MgO}$ & 12.41 & 13.15 & 10.07 & 12.01 & 11.42 & 21.00 & 12.39 & 23.25 & 14.45 & 13.19 \\
\hline $\mathrm{Al}_{2} \mathrm{O}_{3}$ & 17.29 & 15.16 & 14.69 & 16.80 & 18.32 & 11.02 & 21.47 & 2.26 & 15.39 & 17.44 \\
\hline $\mathrm{SiO}_{2}$ & 43.89 & 42.85 & 44.86 & 45.88 & 42.22 & 48.96 & 40.91 & 55.00 & 45.79 & 44.88 \\
\hline $\mathrm{CaO}^{2}$ & 24.08 & 24.25 & 21.57 & 25.33 & 24.84 & 16.32 & 20.93 & 17.61 & 23.36 & 23.48 \\
\hline $\mathrm{Cr}_{2} \mathrm{O}_{3}$ & 0.11 & 0.25 & 0.66 & 0.36 & 1.21 & 0.27 & 1.81 & 0.58 & 0.43 & 0.21 \\
\hline $\mathrm{TiO}_{2}$ & 0.96 & 3.66 & 1.06 & 0.06 & 1.84 & 1.11 & 0.60 & 1.36 & 0.36 & 1.89 \\
\hline $\mathrm{V}_{2} \mathrm{O}_{3}$ & 0.05 & 0.06 & 0.06 & 0.02 & 0.08 & 0.02 & 0.20 & 0.02 & 0.05 & 0.01 \\
\hline MnO & BLD & BLD & 0.37 & BLD & BLD & BLD & BLD & n.a. & 0.01 & n.a. \\
\hline $\mathrm{FeO}$ & 0.55 & 0.07 & 6.85 & 0.12 & 0.21 & 0.71 & 0.82 & 1.40 & 0.58 & 0.15 \\
\hline TOTAL. & 99.34 & 99.45 & 100.19 & 100.58 & 100.14 & 99.41 & 99.13 & 101.48 & 100,42 & 101.25 \\
\hline$S i$ & .598 & 1.568 & 1.659 & $\begin{array}{l}9.647 \\
\end{array}$ & 1.536 & 1.741 & 1.491 & 1.925 & 1.646 & 1.59 \\
\hline$N_{A l}$ & 0.402 & 0.432 & 20.341 & 0.353 & $\begin{array}{ll}3 & 0.464\end{array}$ & 0.259 & 0.509 & $9 \quad 0.075$ & 0.334 & 0.403 \\
\hline Tel. Sum & 2.000 & 2.000 & 2.000 & $0 \quad 2.000$ & $0 \quad 2.000$ & 2,000 & 2.000 & $0 \quad 2.000$ & 2.000 & 2.000 \\
\hline $\mathrm{VI}_{\mathbf{A l}}$ & 0.341 & 0.222 & 0.299 & 0.358 & $\begin{array}{ll}8 & 0.322\end{array}$ & 0.202 & 0.413 & $\begin{array}{ll}3 & 0.018\end{array}$ & 0.298 & 0.328 \\
\hline $\mathrm{Mg}$ & 0.674 & 0.717 & 0.565 & 50.642 & $2 \quad 0.619$ & 1.112 & 0.673 & $3 \cdot 1.212$ & 0.774 & 0.699 \\
\hline $\mathrm{Ca}$ & 0.940 & 0.950 & 0.854 & $4 \quad 0.974$ & $\begin{array}{ll}4 & 0.968\end{array}$ & 0.622 & 0.817 & $7 \quad 0.660$ & 0.899 & 0.895 \\
\hline $\mathrm{Cr}$ & 0.003 & 0.007 & 0.019 & 0.010 & 0.035 & 0.008 & 0.052 & 2.0 .016 & 0.012 & 0.006 \\
\hline $\mathrm{Ti}$ & 0.026 & 0.101 & 0.029 & 0.001 & 0.050 & 0.030 & 0.017 & $7 \quad 0.036$ & 0.010 & 0,051 \\
\hline v & 0.001 & 0.002 & 0.002 & 0 & 0.002 & 0 & 0.005 & 5.0 .001 & 0.001 & 0 \\
\hline $\mathrm{Mn}$ & 0 & 0 & 0.029 & 0 & 0 & 0 & 0 & - & 0 & -. \\
\hline $\mathrm{Fe}$ & 0.017 & 0.002 & 0.212 & 0.004 & $4 \quad 0.006$ & 0.021 & 0.025 & $5: 0.041$ & 0.017 & 0.005 \\
\hline Oct. Sum & 2.002 & 2.001 & 2.009 & $9 \quad 1.989$ & 92.002 & . 1.995 & 2.002 & 2.1 .984 & 2.011 & 1.984 \\
\hline $60 x$ & 4.002 & 4.001 & 4.009 & 3.989 & 4.002 & 3.995 & 4.002 & $2 \quad 3.984$ & 4.011 & 3.984 \\
\hline
\end{tabular}


Pyroxene included in and occurring with in-situ spinel is also mostly aluminous diopside, with the exception of 4377 1 , which has both high- and low-Ca pyroxene with only $\sim 2$ wt $\% \mathrm{Al}_{2} \mathrm{O}_{3}$, in contrast to the $\sim 17 \%$ that is typical of the pyroxene found included in the separated spinels and occurring with the other in-situ spinels.

\section{Olivine}

Analyses of olivine occurring with spinel are given in Table 4. Among the separated spinel grains, there is a bimodal distribution of olivine compositions. With the exception of two samples, spinel either occurs with pure forsterite $\left(\mathrm{Fo}_{>99}\right)$ or with $\mathrm{Fo}_{95-96}$. The pure forsterites all have high $(\sim 1 \mathrm{wt} \%)$ $\mathrm{CaO}$ contents, whereas the grains with more $\mathrm{FeO}$ tend to have lower $\mathrm{CaO}$ but higher $\mathrm{MnO}$ and $\mathrm{Cr}_{2} \mathrm{O}_{3}$ contents than the former (Fig. 8).

Also shown in Fig. 8 are analyses of olivine that occurs with in-situ spinel. Unlike the unzoned olivine in the separates, some olivine in the in-situ occurrences is weakly zoned. The largest crystal in $4377-1$ is zoned from $\mathrm{Fo}_{98}$ to $\mathrm{Fo}_{99}$, and the large subhedral grain in 7-20 is reversely zoned, from $\mathrm{FO}_{95.5}$ to $\mathrm{FO}_{97.8}$. The latter olivine is relatively rich in $\mathrm{CaO}$ $(0.6-0.7 \mathrm{wt} \%) \cdot \mathrm{Cr}_{2} \mathrm{O}_{3}$ contents are high and tend to increase with $\mathrm{FeO}$, but $\mathrm{MnO}$ contents are low and increase slightly with $\mathrm{FeO}$. In 4377-1, the olivine has high $\mathrm{Cr}_{2} \mathrm{O}_{3}$ and $\mathrm{MnO}$ contents and low $\mathrm{CaO} . \mathrm{MnO}$ is anticorrelated with $\mathrm{FeO}$, consistent with loss of iron by reduction (MIYAmOTO et al., 1993). Analyses of the other samples plot along the normal $\mathrm{MnO}-\mathrm{FeO}$ trend for olivine from CM2 chondrites (STEELE, 1990 ). Olivine in $\mathrm{M} 1$ has $\mathrm{Cr}_{2} \mathrm{O}_{3}$ contents which range from $\sim 0.4$ to $0.8 \mathrm{wt} \%$ and do not covary with $\mathrm{FeO}$ or $\mathrm{MnO}$. In the chondrules (6-15 and M92SP1), olivine has $\sim 1-2 \mathrm{wt} \%$ $\mathrm{FeO}$, very low $\mathrm{MnO}$, and lower $\mathrm{CaO}$ than the pure forsterite found with some of the spinel in the separates.

Table 4. Compositions of olivine occurring with spinel.

\begin{tabular}{|c|c|c|c|c|c|c|}
\hline & SP4 & SP50 & SP61 & SP62 & M1 & $4377-1$ \\
\hline $\mathrm{MgO}$ & 55.03 & 51.85 & 53.53 & 56.45 & 53.14 & 56.50 \\
\hline $\mathrm{Al}_{2} \mathrm{O}_{3}$ & 0.54 & 0.28 & 0.32 & 0.30 & 0.10 & 0.12 \\
\hline $\mathrm{SiO}_{2}$ & 42.26 & 41.01 & 41.80 & 41.80 & 41.73 & 41.92 \\
\hline $\mathrm{CaO}$ & 0.77 & 0.27 & 0.29 & 1.03 & 0.30 & 0.24 \\
\hline $\mathrm{TiO}_{2}$ & 0.07 & 0.06 & 0.07 & 0.06 & 0.04 & 0.08 \\
\hline $\mathrm{V}_{2} \mathrm{O}_{3}$ & 0.05 & 0.02 & 0.03 & 0.03 & 0.02 & 0.02 \\
\hline $\mathrm{Cr}_{2} \mathrm{O}_{3}$ & 0.46 & 0.57 & 0.65 & 0.24 & 0.63 & 0.61 \\
\hline Mno & BLD & 0.09 & 0.07 & BLD & 0.05 & 0.19 \\
\hline $\mathrm{FeO}$ & 0.31 & 5.23 & 3.88 & 0.64 & 4.26 & 1.06 \\
\hline TOTAL & 99.49 & 99.391 & 100.64 & 100.55 & 100.27 & 100.74 \\
\hline $\mathrm{Si}$ & 0.999 & 0.992 & 0.992 & 0.982 & 0.996 & 0.98 \\
\hline $\mathrm{Mg}$ & 1.938 & 1.870 & 1.894 & 1.976 & 1.890 & 1.97 \\
\hline $\mathrm{Al}$ & 0.015 & 0.008 & 0.009 & 0.008 & 0.003 & 0.00 \\
\hline $\mathrm{Ca}$ & 0.019 & 0.007 & 0.007 & 0.026 & 0.008 & 30.00 \\
\hline $\mathrm{Ti}$ & 0.001 & 0.001 & 0.001 & 0.001 & 0.001 & 0.00 \\
\hline V & 0.001 & 0 & 0 & 0.001 & 0 & 0 \\
\hline $\mathrm{Cr}$ & 0.009 & 0.011 & 0.012 & 0.005 & 0.012 & 20.011 \\
\hline Mn & 0 & 0.002 & 0.001 & 0 & 0.001 & 0.004 \\
\hline $\mathrm{Fe}$ & 0.006 & 0.106 & 0.077 & 0.013 & 0.085 & $5 \quad 0.02$ \\
\hline $\begin{array}{l}\text { Total } \\
\text { cations/4 ox }\end{array}$ & 2.988 & 2.997 & 2.993 & 3.012 & 2.996 & 53.00 \\
\hline
\end{tabular}

BLD: below limit of detection of 0.004 wt \% MnO. $\mathrm{NiO}$ and $\mathrm{Sc}_{2} \mathrm{O}_{3}$ were looked for but not detected.

\section{MURCHISON OLIVINE}
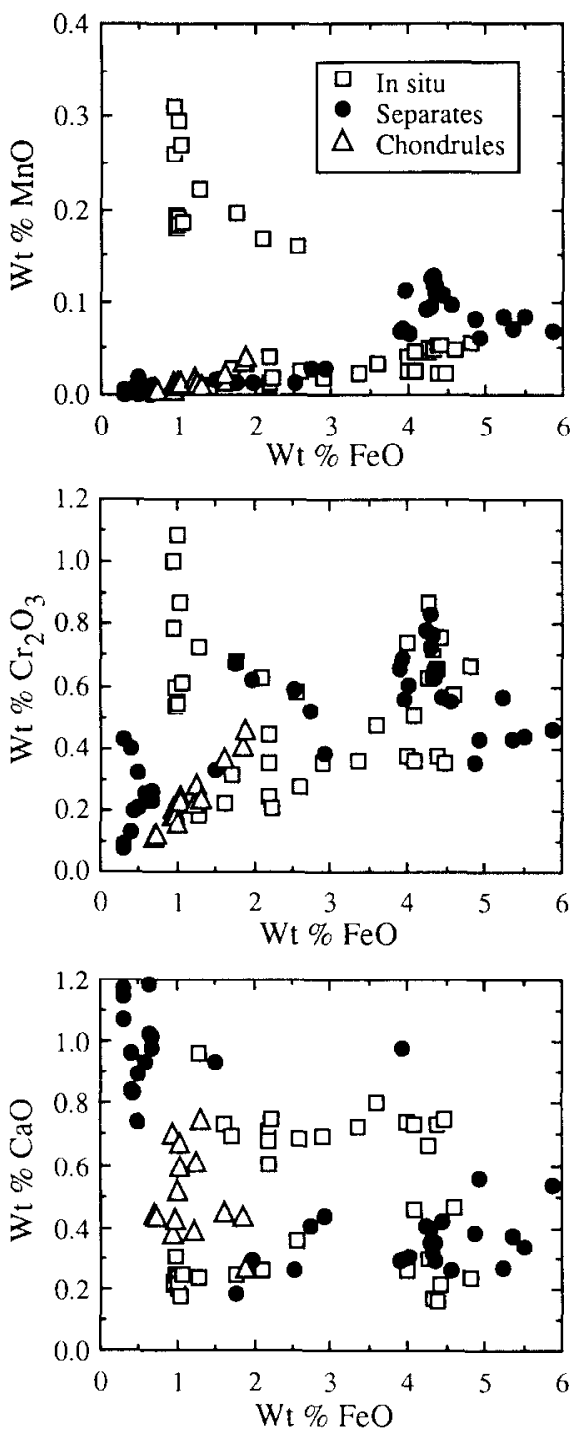

FIG. 8. Plots of $\mathrm{MnO}, \mathrm{Cr}_{2} \mathrm{O}_{3}$, and $\mathrm{CaO}$ vs. $\mathrm{FeO}$ contents in olivine associated with spinel.

\section{Glass}

Five spinel grains have inclusions of $\mathrm{Si}-, \mathrm{Al}-, \mathrm{Ca}$-rich glass (Table 5). Four of the spinels are patchy and one has chevrontype zoning. The glasses are generally similar to, but have less $\mathrm{MgO}$ than, glass inclusions found in isolated olivine crystals in Murchison (FuCHS et al., 1973) whose average composition is also given in Table 5 . The glasses found in spinel also bear some similarity to glasses found in ferromagnesian chondrules in ordinary chondrites (JONES and SCOTT, 1989; JONES, 1992), but the glasses reported here have lower $\mathrm{MgO}$ and $\mathrm{Na}_{2} \mathrm{O}$ contents than chondrule glass.

\section{Other Associated Phases}

Many of the spinel grains either enclose or are attached to small amounts of Fe-rich silicate, analyses of which are given in Table 6. Low totals indicate that it is a hydrous phase and, 
Table 5. Compositions of glass inclusions in Murchison spinels.

\begin{tabular}{|c|c|c|c|c|c|}
\hline & SP44 & SP54 & SP63 & SP64 & Olivine* \\
\hline $\mathrm{MgO}$ & 35 & 1.92 & 2.45 & 2.91 & 4.2 \\
\hline $\mathrm{Al}_{2} \mathrm{O}_{3}$ & 22.85 & 24.84 & 23.47 & 23.73 & 216 \\
\hline $\mathrm{SiO}_{2}$ & 47.95 & 52.38 & 53.47 & 61.02 & 52.1 \\
\hline $\mathrm{CaO}$ & 23.41 & 20.32 & 18.18 & 12.91 & 18.1 \\
\hline $\mathrm{TiO}_{2}$ & 1.84 & 0.96 & 0.36 & 0.71 & 0.8 \\
\hline $\mathrm{V}_{2} \mathrm{O}_{3}$ & 0.05 & 0.05 & 0.36 & BLD & nat. \\
\hline $\mathrm{Cr}_{2} \mathrm{O}_{3}$ & 0.44 & 0.44 & 0.47 & 0.21 & 0.2 \\
\hline $\mathrm{MnO}$ & n.a. & 0.02 & 0.08 & 0.02 & 0.03 \\
\hline $\mathrm{FeO}$ & 0.30 & 0.28 & 0.58 & 0.61 & 1.3 \\
\hline
\end{tabular}

$\begin{array}{lllll}\text { TOTAL } & 100.19 & 101.21 & 99.42 & 102.12\end{array}$

л.a.: not analyzed. BLD: below limit of detection of 0.005 wt $\% \mathrm{~V}_{2} \mathrm{O}_{3}$.

*Average of eleven analyses of glass in isolated olivine crystals (FUCHS et al., 1973).

in some cases, is similar in composition to that found in Murchison CAIs (MACPHERSON et al., 1984a). The phyllosilicates in SP71 and SP78 are fairly S-rich, however, and are probably mixtures of cronstedtite. serpentine, and an $\mathrm{Fe}-, \mathrm{S}-, \mathrm{O}-, \mathrm{Ni}$-bearing phyllosilicate found in $\mathrm{CM} 2$ matrices (TOMEOKA and BUSECK, 1985).

\section{ISOTOPIC COMPOSITION OF SPINEI.}

\section{Oxygen}

The oxygen isotopic compositions measured in the Burma spinel standard and twelve separated spinel grains are given in Table 7 and are plotted in Fig. 9, along with those of spinel-rich acid residue 2C10c (CLAYTON and MAYEDA, 1984 ) and the average of nine $\mathrm{Mg}$-, Al-rich spinel grains from acid residue CFOc (VIRAG et al., 1991), both from Murchison. In the oxygen 3-isotope diagram, the spinel samples from the present study plot in a cluster close to the intersection of the terrestrial fractionation line and the unit slope mixing line for refractory phases from carbonaceous chondrites (CLAYTON et al., 1977). The scatter of the oxygen isotopic compositions measured on different standard grains (Table 7) considerably excecds the precision of single analyses. probably reflecting variations in the geometry of individual grains. The errors given in Table 7 express only the error of the mean of numerous measurements on each grain, and are smaller for the Murchison spinels because more measurements were made on each grain of the latter. An uncertainty corresponding to the grain-to-grain variation of the Burma spinel data points must be superimposed on the Murchison

Table 6. Compositions of Fe-rich alteration products.

\begin{tabular}{lcrrrr}
\hline & \multicolumn{1}{c}{ SP70 } & \multicolumn{1}{c}{ SP71 } & \multicolumn{1}{c}{ SP78 } & \multicolumn{1}{c}{$\mathrm{MI}$} & $4377-1$ \\
\hline $\mathrm{MgO}$ & 10.19 & 16.83 & 7.15 & 5.59 & 7.00 \\
$\mathrm{Al}_{2} \mathrm{O}_{3}$ & 2.99 & 5.22 & 3.85 & 2.95 & 4.98 \\
$\mathrm{SiO}_{2}$ & 25.32 & 25.39 & 13.52 & 22.48 & 23.93 \\
$\mathrm{CaO}$ & 0.40 & 0.70 & 0.25 & 0.04 & 0.05 \\
$\mathrm{P}_{2} \mathrm{O}_{5}$ & $\mathrm{BLD}$ & 0.05 & 0.07 & $\mathrm{BLD}$ & $\mathrm{BLD}$ \\
$\mathrm{SO}_{3}$ & 0.08 & 7.82 & 15.42 & 0.16 & 0.43 \\
$\mathrm{TiO}_{2}$ & 0.09 & 0.10 & 0.06 & 0.04 & 0.07 \\
$\mathrm{Cr}_{2} \mathrm{O}_{3}$ & 0.68 & 0.41 & 2.01 & 0.98 & 0.59 \\
$\mathrm{FeO}$ & 49.85 & 30.88 & 48.85 & 53.67 & 49.78 \\
$\mathrm{NiO}$ & $\mathrm{BLD}$ & 1.23 & 2.02 & $\mathrm{BLD}$ & $\mathrm{BLD}$ \\
$\mathrm{TOTAL}$ & 89.61 & 88.63 & 93.20 & 85.91 & 86.83 \\
\hline
\end{tabular}

* $\mathrm{S}$ reported as $\mathrm{SO}_{3}$ but its oxidation state is unknown BLD: below limit of detection- $-0.021 \mathrm{wt} \%$ for $\mathrm{P}_{2} \mathrm{O}_{5}$; $0.057 \mathrm{wt} \% \mathrm{NiO}$.

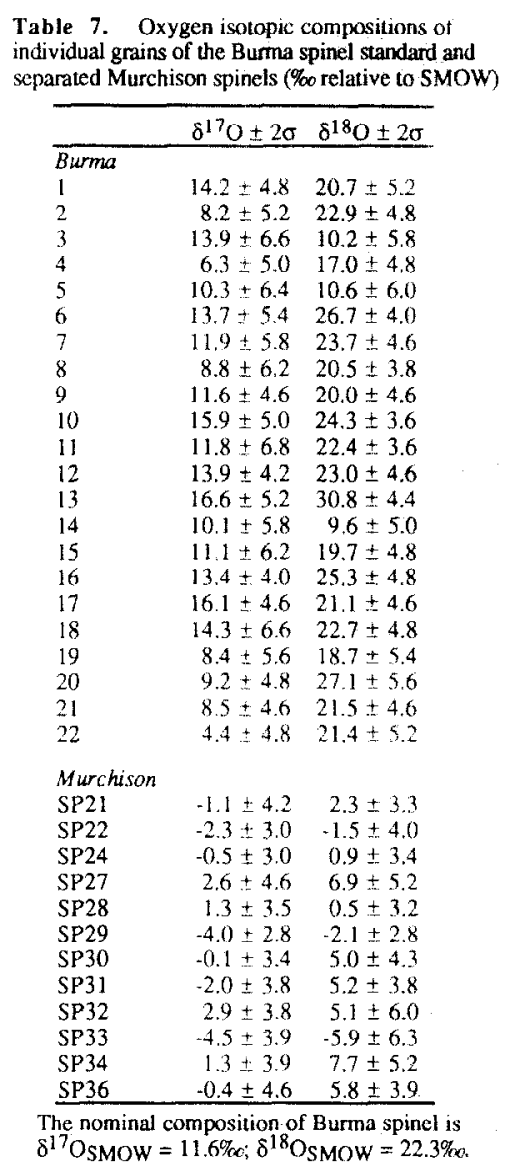

spinel data. The scatter of Murchison data points is comparable to that shown by those obtained from individual Burma spinel grains. The Murchison spinel data points are thus compatible with a single oxygen isotopic composition.

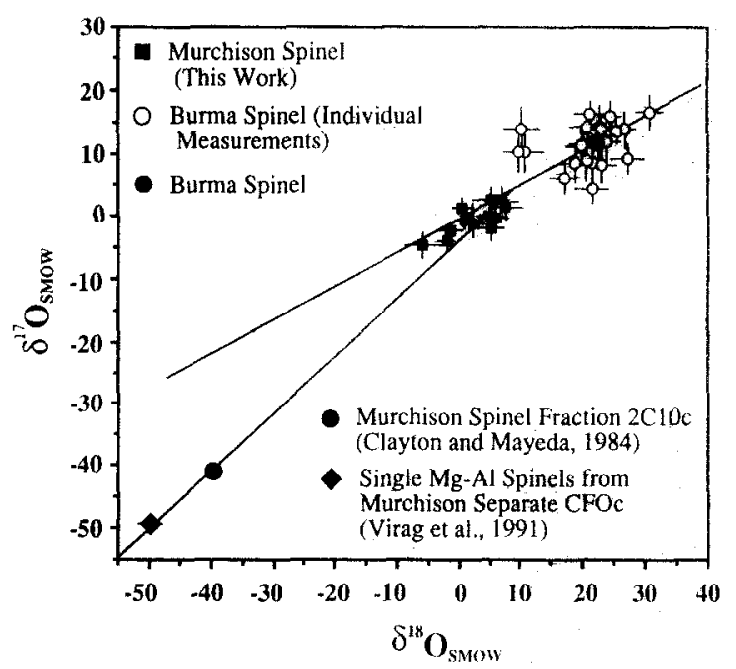

FIG. 9. Oxygen isotopic compositions of Murchison spinels. Analyses of the Burma spinel standard are also given. The stippled circle represents the average of the individual Burma spinel analyses. The solid diamond represents the average of nine spinels from acid residue CFOc. The spinels analyzed for this study have oxygen isotopie compositions that plot on or near the terrestrial fractionation linc. unlike those found in acid residues $2 \mathrm{ClO} \mathrm{c}$ and $\mathrm{CFOC}$. 
What is most striking is that this composition is essentially normal, in pronounced contrast to the ${ }^{16} \mathrm{O}$-rich compositions found in Mg-, Al-rich spinel from Allende and Vigarano inclusions (CLAYTON et al., 1977; ZINNER et al., 1991), in the spinel-rich acid residue, $2 \mathrm{C} 10 \mathrm{c}$, from Murchison (CI.AYTON and MAYEDA, 1984), in individual spinel grains from another Murchison acid residue, CFOc (MCKEEGAN, 1987; VIRAG et al., 1991), and in hibonite and corundum samples from Murchison (FAHEY et al.. 1987; VIRAG et al., 1991; IRELAND et al., 1992).

Previous indications of a wide range of oxygen isotopic compositions of Murchison spinel come from ion microprobe studies of individual spinel grains from the CFOc acid residue. ZINNER and EPSTEIN (1987) reported $\delta^{18} \mathrm{O}$ values ranging from +9 to $-55 \%$ from individual $\mathrm{Mg}$-spinel grains identified on the basis of qualitative analysis of energy-dispersive $X$ ray spectra. MCKEEGAN ( 1987 ) used energy-dispersive spectra to distinguish spinel from chromite grains in this residue and measured both $\delta^{18} \mathrm{O}$ and $\delta^{17} \mathrm{O}$ in individual grains. Most of the grains lie along the unit-slope oxygen isotope mixing line, with some individual spinel grains plotting at lower $\delta^{18} \mathrm{O}$ and some at higher $\delta^{18} \mathrm{O}$ values than that of the bulk acid residue 2C10c of CLAYTON and MAYEDA (1984). The only chromite grain reported by MC KEEGAN (1987) plots at $\delta^{18} \mathrm{O}$ $=-22$, much closer to the terrestrial fractionation line than all of the $\mathrm{Mg}$-spinel grains except one. The CFOc grains whose oxygen isotopic compositions were measured by VIRAG et al. (1991) were selected to be Mg-, Al-spinel by energy-dispersive spectra, and their $\mathrm{Cr}$ and Fe concentrations, 80-1500 and $500 \mathrm{ppm}$. respectively, were measured by ion microprobe. Not included in the average of the spinel grains from CFOc in Fig. 9 is one data point that plots at $\delta^{18} \mathrm{O}=0 \%$, in the region of the spinels of the present study (see Fig. $2 \mathrm{~b}$ of VIRAG et al., 1991). It is noteworthy that the $\mathrm{Cr}$ and $\mathrm{Fe}$ concentrations in this grain, 4050 and $6100 \mathrm{ppm}$, respectively (A. Virag, pers. commun.), are substantially higher than in the other CFOc grains, and within the ranges of the spinel grains of the present study.

\section{Chromium}

Results for ${ }^{53} \mathrm{Cr}$ and ${ }^{54} \mathrm{Cr}$ abundances are reported in Table 8 as $f$-unit ( parts in $10^{4}$ ) deviations from the terrestrial normal compositions reported by PAPANASTASSIOU (1986). The data are also plotted in Fig. 10. Within rather variable error limits

Table 8. Cr isotopic data for Murchison spinels.

\begin{tabular}{lrrrrr}
\hline Sample & $N^{(a)}$ & $\chi^{2} 53^{(b)}$ & $\chi_{54}{ }^{(b)}$ & $\varepsilon_{53}(\mathrm{c})$ & $\varepsilon_{54}(\mathrm{c})$ \\
\hline Reagent Cr & 31 & 1.1 & 1.0 & $1.3 \pm 0.8$ & $5.4 \pm 1.4$ \\
Burma Spinel & 8 & 1.3 & 0.5 & $-0.5 \pm 2.0$ & $-1.5 \pm 3.8$ \\
SP27 & 2 & 1.2 & 5.4 & $3.0 \pm 2.6$ & $1.7 \pm 5.4$ \\
SP28 & 5 & 1.7 & 0.8 & $3.3 \pm 1.8$ & $4.2 \pm 3.6$ \\
SP29 & 2 & 0.1 & 0.5 & $2.1 \pm 5.2$ & $-11.3 \pm 10.4$ \\
SP30 & 2 & 0.4 & 0.4 & $-2.5 \pm 3.4$ & $-3.4 \pm 5.8$ \\
SP31 & 13 & 1.7 & 1.4 & $-0.6 \pm 1.0$ & $2.5 \pm 2.0$ \\
SP34 & 6 & 1.7 & & $-3.4 \pm 2.4$ & $-10.2 \pm 10.2$ \\
\hline
\end{tabular}

(a) Number of runs for given sample.

(b) Reduced chi-squared for individual runs relative to their mean.

(c) Deviation from terrestrial normal $\left({ }^{53} \mathrm{Cr} /{ }^{52} \mathrm{Cr}=0.113459\right.$, $\left.{ }^{34} \mathrm{Cr} /{ }^{2} \mathrm{Cr}=0.0282129\right)$ of PAPANASTASSIOU $(1986)$, in parts per $10^{4}$; stated errors are two-sigma deviations of the mean of all runs (see text for probable limitations on formal convergence of the mean).

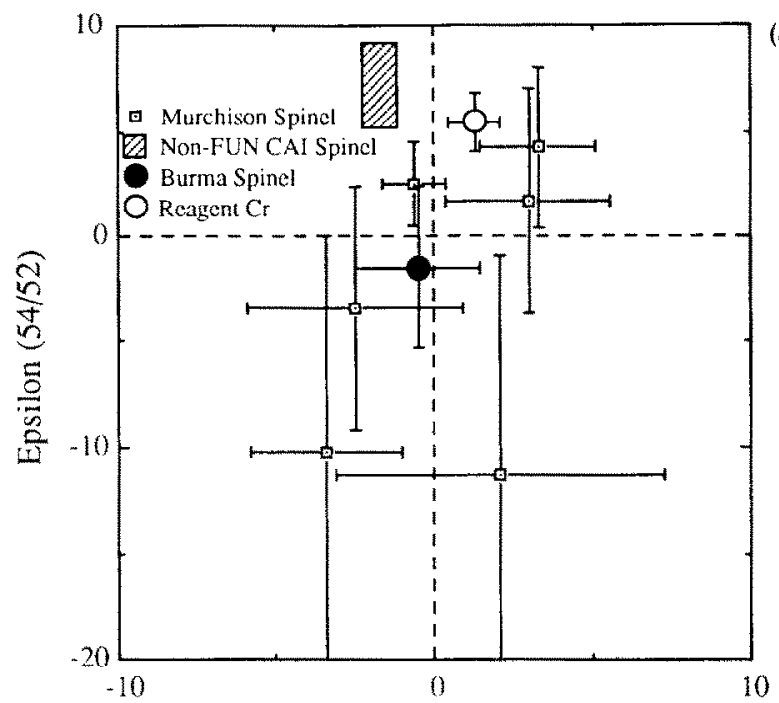

(a)

Epsilon (53/52)

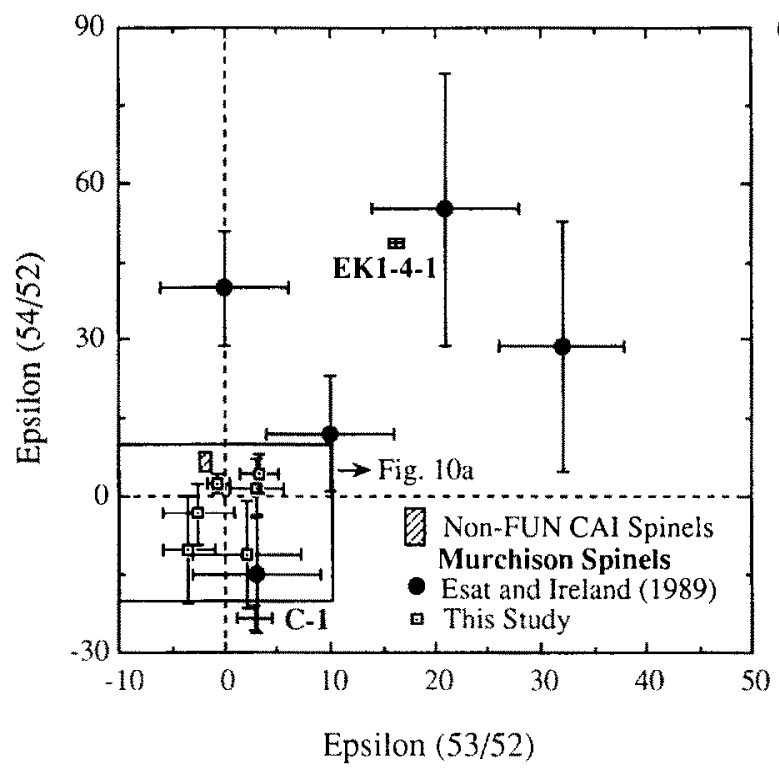

(b)

FIG. 10. (a) Chromium isotopic compositions of Murchison spinel, non-FUN CAl spinel (PAPANASTASSIOU, 1986; BIRCK and ALIEGRE;, 1988), and $\mathrm{Cr}$ standards. (b) Chromium isotopic compositions of Murchison spinel analyzed by ESAT and IRELAND (1989) and, for reference, compositions in FUN inclusions $\mathrm{C}-1$ and $\mathrm{EK}$ 1-4-1 (PAPANASTASSIOU, 1986). The anomalous ratios determined by ESAT and IRELAND (1989) are not observed in the samples studied here.

the data for the individual Murchison spinel grains are consistent. or very nearly so, with normal chromium isotopic composition. It is evident that these data do not support any arguments for isotopic anomalies in chromium in these spinels. The data indicate that chromium in these spinels is isotopically uniform. within less than one $\%$.

\section{DISCUSSION}

\section{Origins and Sources}

\section{Homogeneous and gradational grains}

Spinel grains of these types are found in igneous settings. EL. GORESY et al. (1971), for example. illustrated gradational 
zoning in very Ti-. Cr-rich spinel grains in Apollo 12 basalts. In addition, chondrules crystallized from liquids, and our observation of homogeneous spinel in two chondrules (Fig. 2e. () suggest chondrules are a possible source for this type of spinel, even though the spinel grains in the chondrules are smaller than the separated spincls. In SP6I and SP73, the two homogeneous spinel samples that occur with olivine, there is clear textural evidence that olivine crystallized before spinel. Igneous crystallization of spinel after olivine might appear to be a problem because most chondrules have very high normative olivine contents and, in melts with these compositions, olivine is typically followed in the crystallization sequence by pyroxene or chromite, but not $\mathrm{Mg}$ Al- Cr-spinel. The mineralogy and textures of two spinelbearing chondrules from Murchison, M92SPl ( Fig. 2e) and 6-15 (Fig. 2f), indicate. however, that liquids did exist from which spinel could crystallize after forsteritic olivine. Both of these chondrules contain spinel crystals that grew around the end of an olivine crystal, and a fragment with a similar tcxture was found in the separates. The similarity of these occurrences is evident from the close-up views in Fig. 11. To
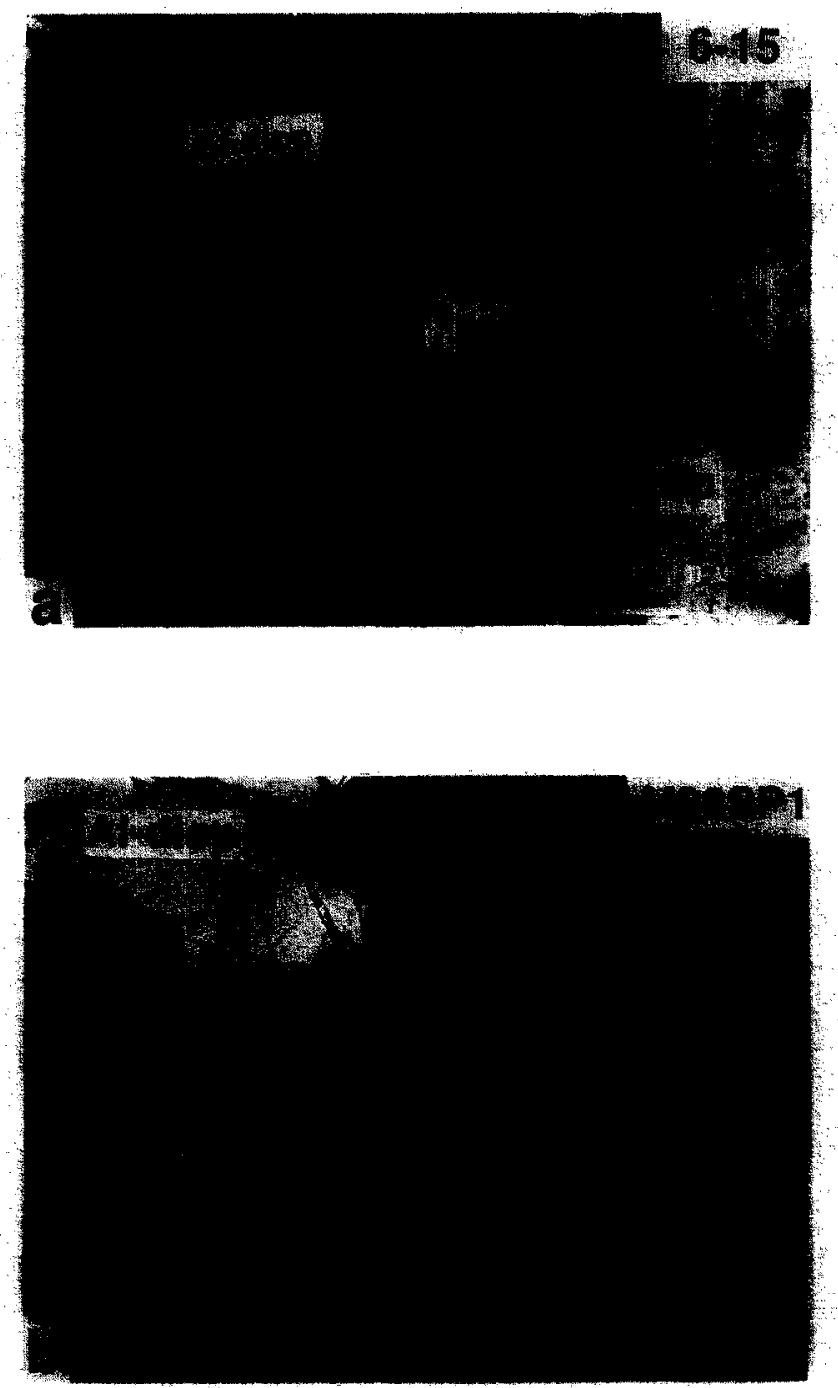

better understand these chondrules, we calculated ther bulk compositions from the average mineral compositions and their abundances, and the results are given in Table 9 . Note that the compositions are $\mathrm{Al}_{2} \mathrm{O}_{3}-\mathrm{rich}$ and $\mathrm{FeO}$-poor relative to those of typical chondrules in $\mathrm{CM} 2$ chondrites (column 3 in Table 9), which average -2 wt $\mathrm{Al}_{2} \mathrm{O}_{3}$ and $-14 \mathrm{wt}^{2}$ FeO (OSBORN et al. 1974). These features of the compositions of the latter chondrules cause their residual liquids at the end of olivine crystallization to be $\mathrm{Al}_{2} \mathrm{O}_{3}$-poor and $\mathrm{FeO}$ rich, and chromite, not aluminous spinel, follows olinte fe. IOHNSON and PRINZ, 1991).

Phase equilibria clarify why, in M92SPl and 6-15. aluminous spinel crystallized after olivine. For carly stages of crystallization, we refer to Fig. $12 \mathrm{a}$, which shows the relations for the $15 \mathrm{wt}_{2}-\mathrm{Al}_{2} \mathrm{O}_{3}$ plane in the $\mathrm{CaO}-\mathrm{MgO}-\mathrm{Al}_{2} \mathrm{O}_{3}-\mathrm{SiO}_{2}$ (CMAS) system, because the composition of M92SP I falls on this plane. and the composition of the residual liquid in $6-15$ enters this plane after $45 \%$ crystallization of olivime. The samples plot low in the forsterite field. Crystallization of forsterite from melts with these compositions would enrich the residual liquids in $\mathrm{Al}_{2} \mathrm{O}_{3}$ and drive their compositions

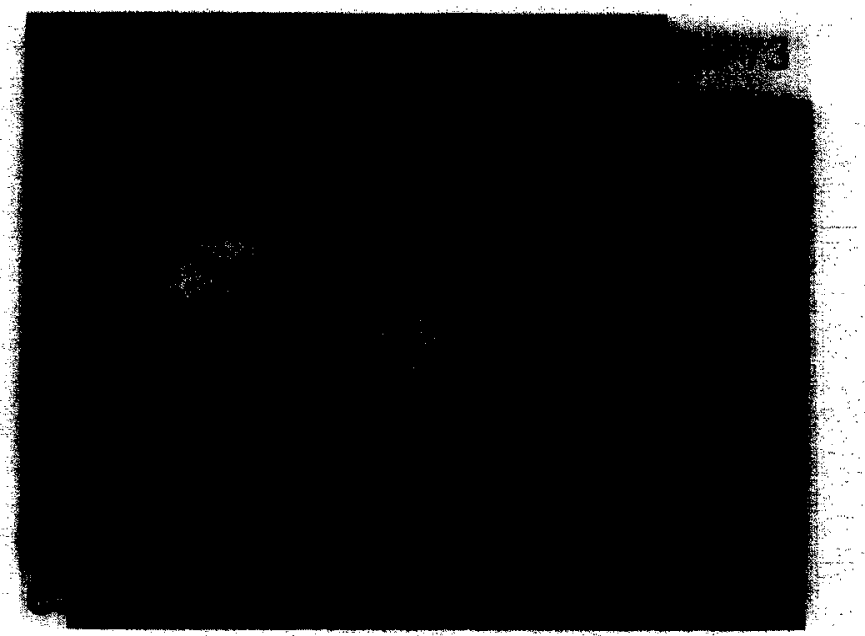

Fici. 11. BEl of spinel partially enclosing subhedral olivine in assemblages which have not been recrystallized. Note the angular of ivine-spinel contacts. Extent of spinel crystals is indicated in (a) and (b). Scale bars are $10 \mu \mathrm{m}$. Abbreviations as used previously. (a) Close-up of chondrule 6-15. (b) Close-up of chondrule M92SP1. (c) Separated sample SP73. 
Table 9. Bulk compositions of chondrules.

\begin{tabular}{|c|c|c|c|c|c|c|}
\hline & $6-15$ & M92SP1 & $\begin{array}{c}\mathrm{C} 2 \\
\text { chondrules }\end{array}$ & $\mathrm{RCO}^{2} 1^{2}$ & $\mathrm{RCO}^{2} 2^{2}$ & $\begin{array}{r}\text { ALHA } \\
77299^{3} \\
\end{array}$ \\
\hline $\mathrm{Na}_{2} \mathrm{O}$ & n.a. & n.a. & 0.1 & 2.8 & 5.9 & 3.4 \\
\hline $\mathrm{MgO}$ & 44.0 & 35.4 & n.a. & 14.1 & 4.4 & 8.3 \\
\hline $\mathrm{Al}_{2} \mathrm{O}_{3}$ & 8.5 & 15.9 & 1.9 & 20.5 & 24.0 & 22.8 \\
\hline $\mathrm{SiO}_{2}$ & 40.2 & 37.0 & 39.2 & 37.8 & 47.6 & 43.4 \\
\hline $\mathrm{CaO}$ & 5.9 & 8.8 & n.a. & 3.2 & 4.2 & 8.7 \\
\hline $\mathrm{TiO}_{2}$ & 0.4 & 0.5 & n.a. & 0.8 & 1.3 & 1.3 \\
\hline $\mathrm{Cr}_{2} \mathrm{O}_{3}$ & 0.3 & 1.3 & 0.5 & 3.2 & 2.9 & 0.9 \\
\hline $\mathrm{FeO}$ & 0.7 & 0.8 & 13.6 & 10.6 & 5.8 & 8.7 \\
\hline
\end{tabular}

n.a.: not analyzed.

${ }^{1}$ Average of INAA analyses of 77 chondrules from several $\mathrm{C} 2$

chondrites (OSBORN et al., 1974).

${ }^{2}$ Broad-beam electron probe analysis of $\mathrm{Cr}$-spinel-bearing chondrulc in Roosevelt County L chondrites (MCCOY et al., 1991). They also reported 6.7 wi \% FeNi in RC 071.

${ }^{3}$ Broad-beam electron probe analysis of a spinel-bearing chondrule ( $\$ 20$ ) from ALHA 77299 , an H3 chondrite (RISCHOFF and KEIL, 1983).

directly away from forsterite toward the forsterite-spinel cotectic, as shown by the arrows through the data points in Fig. $12 \mathrm{a}$. With increasing $\mathrm{Al}_{2} \mathrm{O}_{3}$ contents in the system, the spinel field expands, effectively causing the forsterite-spinel cotectic to move to the right in Fig. 12a. The dashed lines in the forsterite field give the approximate locations of the forsteritespinel cotectic at 16,17 , and $18 \mathrm{wt} \% \mathrm{Al}_{2} \mathrm{O}_{3}$ and are labelled accordingly. For M92SP1, crystallization of only $\sim 10 \mathrm{wt} \%$ forsterite yields a residual liquid with $\sim 17.5 \mathrm{wt} \% \quad \mathrm{Al}_{2} \mathrm{O}_{3}$, where it reaches the spinel-forsterite cotectic. The residual liquid composition in 6-15 shown in Fig. 12a reaches spinel saturation after crystallization of an additional $7 \mathrm{wt} \%$ olivine.

Figure $12 \mathrm{~b}$ is the gehlenite-anorthite-forsterite plane in CMAS, projected from spinel according to the method of STOLPER (1982). On it we plot the compositions of residual liquids in M92SP1 and 6-15 from which spinel should begin to crystallize. As shown by the lines through the data points in Fig. 12b, the equilibrium phase relations indicate that forsterite + spinel should be joined first by anorthite and then by pyroxene. From the petrography of the chondrules, however, we know that pyroxene followed forsterite + spinel. Apparently the crystallization of anorthite was suppressed and crystallization of forsterite + spinel continued until the liquid composition reached a metastable extension (dashed line in anorthite field) of the pyroxene-forsterite-spinel cotectic. This situation is analogous to late-stage crystallization in some Type B CAIs, in which melilite + spinel crystallization proceeded until a metastable extension of the melilitepyroxene-spinel cotectic was encountered (MACPHERSON et al., 1984b), causing pyroxene to crystallize before anorthite. YANG (1975) found that pyroxene crystallizing at invariant point $R$ on Fig. 12 b contains $\sim 20 \% \mathrm{Al}_{2} \mathrm{O}_{3}$, while $\mathrm{A}$. $\mathrm{H}$. Treiman (pers, commun.) found an average of $11.5 \% \mathrm{Al}_{2} \mathrm{O}_{3}$ in pyroxene that crystallized at invariant point $Q$, suggesting that virtually all pyroxene crystallizing in this system is highly aluminous. While it is unclear how anorthite supersaturation will affect the $\mathrm{Al}_{2} \mathrm{O}_{3}$ content of pyroxene forming along the metastable extension of the pyroxene-forsterite-spinel cotectic, values approaching $17 \%$, like the $\mathrm{Al}_{2} \mathrm{O}_{3}$ contents of the pyroxene in chondrules 6-15 and M92SP1, do not seem unreasonable.

We have also observed gradational-type spinel grains in a chondrule (Fig. 2e, upper left), as did BISCHOFF and KEIL

(1984) and MCCOY et al. (1991) who reported subhedral to euhedral, gradational-type spinel grains $\sim 100 \mu \mathrm{m}$ across that appear to have nucleated at the margins of Al-rich chondrules in ordinary chondrites. The $\mathrm{FeO}$ and $\mathrm{Cr}_{2} \mathrm{O}_{3}$ contents of these spinel grains decrease with increasing distance from the crystal edge nearest the chondrule rim. Similarly, in two of the separated spinels with gradational-type zoning, SP27 and SP42. $\mathrm{FeO}$ increases with increasing $\mathrm{Cr}_{2} \mathrm{O}_{3}$. Both MrCoy et al. (1991) and BISCHOFF and KEIL ( 1984) attributed the observed zoning to fractional crystallization. Based on their

(a)

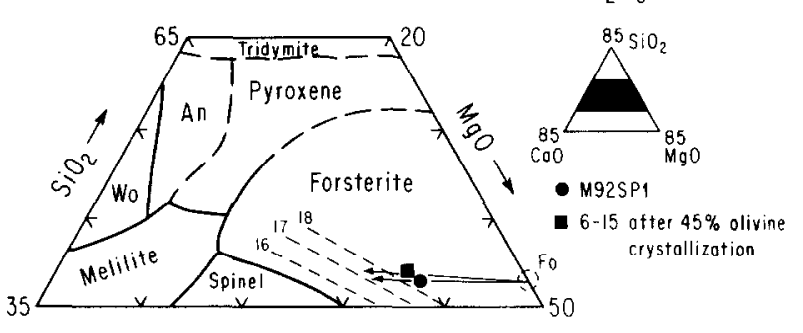

(b)

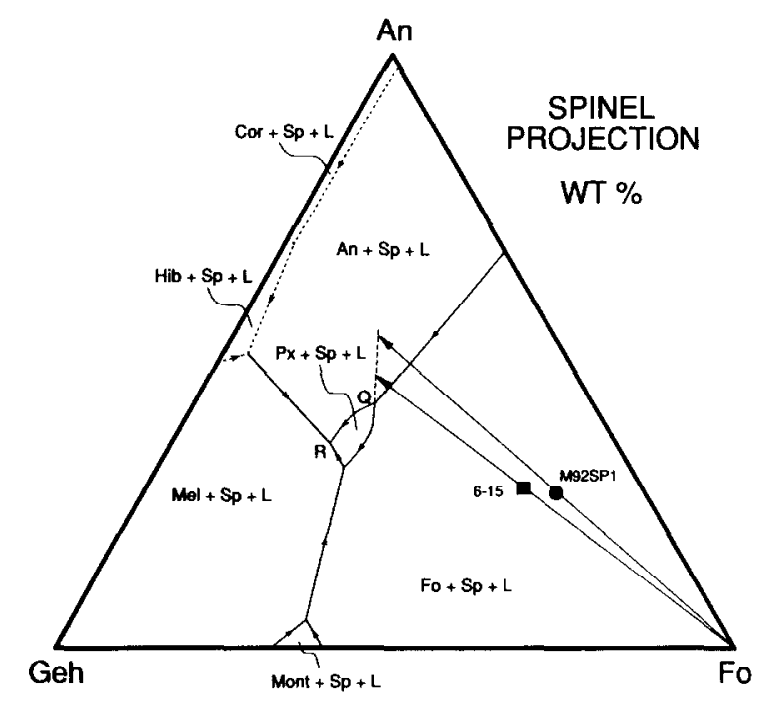

FiG. 12. (a) Part of the $15 \mathrm{wt} \%-\mathrm{Al}_{2} \mathrm{O}_{3}$-plane in CMAS. Compositions of Murchison spinel-bearing chondrules $6-15$ (after $45 \%$ crystallization of olivine) and M92SP1 are shown, as are the approximate locations of the forsterite-spinel cotectic at different bulk $\mathrm{Al}_{2} \mathrm{O}_{3}$ contents, showing how the spinel field expands with increasing $\mathrm{Al}_{2} \mathrm{O}_{3}$. As the chondrules crystallize olivine, the composition of the residual liquid moves toward the forsterite-spinel cotectic, as indicated by the arrows from forsterite ( $F o$ ) through the data points. An: anorthite. Wo: wollastonite. After OSBORN et al. (1954). (b) Projection, in weight percent, from spinel onto the gehlenite-anorthite-forsterite plane in the system $\mathrm{CaO}-\mathrm{MgO}-\mathrm{Al}_{2} \mathrm{O}_{3}-\mathrm{SiO}_{2}$. Two Al-rich Murchison chondrules ( see text) plot in the forsterite field. Crystallization of forsterite plus spinel drives residual liquid compositions away from the forsterite apex into the anorthite field (lines from Fo through data points). Absence of anorthite from these chondrules suggests that anorthite crystallization was kinetically delayed and forsterite crystallization continued until a metastable extension (dashed line, no arrows) of the pyroxene-forsterite cotectic was encountered. $\mathrm{Sp}$ : spinel; Fo: forsterite; An: anorthite; Cor: corundum; Hib: hibonite: Px: pyroxene; Geh: gehlenite; Mel: melilite; Mont: monticellite; L: liquid. $R$ and $Q$ are invariant points discussed in the text. After STOLPER (1982). 
coarse, euhedral nature. the spinel crystals in these chondrules formed early, probably nucleating on the edges of the chondrules and growing inward, resulting in their asymmetric zoning. If the gradational-type spinel grains in our suite are representative of complete crystals, then it is likely that they formed in a similar way, i.e., by nucleation on the surface of a chondrule or on another grain in a chondrule. followed by growth away from the attached edge. Bulk compositions of these three gradational spinel-bearing chondrules are given in Table 9 (columns 4-6). It is interesting to note that these chondrules in which spinel crystallizes early, if not first, have higher $\mathrm{Al}_{2} \mathrm{O}_{3}$ contents $(>20$ wt $)$ than $\mathrm{M} 92 \mathrm{SP} 1$ and $6-15$. in which olivine crystallized first. As suggested by the expansion of the spinel field at the expense of the forsterite field shown in Fig. $12 \mathrm{a}$, increasing $\mathrm{Al}_{3} \mathrm{O}_{3}$ contents in chondrules of these compositions increase the probability that spinel crystallizes before forsterite. If our proposed origins for the separated homogeneous and gradational spinels are correct, then it is likely that the gradational spinels came from chondrules that were more $\mathrm{Al}_{2} \mathrm{O}_{3}$-rich than the source chondrules of the homogeneous spinels.

An argument against chondrules being a source of the homogeneous and gradational spinels. however, is the difference in size between those in the separates and those in the chondrules. The homogeneous and gradational spinel grains studied here range from 50 to $180 \mu \mathrm{m}$ in diameter. with an average of $100 \mu \mathrm{m}$, while the largest spinel we have seen in a chondrule is $45 \mu \mathrm{m}$. The discrepancy in size is greater than this. since most of the separated grains in this study are fragments of even larger crystals. The spinel-bearing chondrules discussed above are themselves $\sim 7-15$ times the average spind size. If the same were true for the putative parent chondrules of the separated spinels, those chondrules would have to have been in excess of $1.3-2.7 \mathrm{~mm}$ in diameter to account for the largest spinel crystals. Chondrules that contain coarse, Alrich. Cr-bearing spinel grains are exceedingly rare in Murchison, as are chondrules of this Size. OLSEN and GROSSMAN (1978) found that Murchison chondrules range in diameter from 175 to $1081 \mu \mathrm{m}$, with a mean of only $420 \mu \mathrm{m}$. The minimum chondrule size necessary to account for the largest homogeneous and gradational spinel grains in our separates is thus $16 \%$ larger than the largest chondrule reported from Murchison, and the average separated spincl would probably require a parent chondrule equal in size to the largest chondrule seen in Murchison. If the homogeneous and gradational spinel grains in the separates originated in chondrules, it is clear that those chondrules are from a population that is not only more aluminous but also much larger on average than that seen in Murchison. Inclusions MI and 4377-1 do not have round shapes. so it could be argued that they may be remnants of such chondrules.

\section{Corcerim grains}

Concentrically zoned spinel grains were reported from Apollo 12 basalts by EL GORFSY et al. (1976). They are much more $\mathrm{Ti}$ - and $\mathrm{Cr}$-rich than those seen here and their cores are either idiomorphic or rounded, in contrast to the irregular, embayed cores in the grains studied here. This type of grain occurs in chondrule M92SPI (Fig. 2e, bottom) and in some plagioclase-olivine inclusions in the 3 chondrites Allende (SHive et al., 1991 ) and Ningiang (A. M. Davis, pers. commun.). The grains in M92SPl have irregularly shaped Mg-poor cores with diffuse core-rim boundaries; those among the separated grains and those described by SHEN c1 al. (1991) have sharp, corroded core-rim boundaries SHING et al. (1991) interpreted the (core-rim) zoned spinels that they observed as relict grains in which the Cr-poor cores survived melting of the host inclusion, and relatively $\mathrm{Cr}$-rich spinel enclosed them during subsequent crystallization. Another way to derive core-rim spinel grains from a liquid. as shown by FISK and BENCF (1980). is for plagioclase to begin to cocrystallize with spinel. This increases the $\mathrm{C} / \mathrm{N} / \mathrm{latio}$ of the residual liquid and of the crystallizing spinel, but this sequence would only give rise to zoned spinels with corroded cores if, prior to plagioclase crystallization, the liquid composition had left the spinel stability field. causing the spinel to begin to react with the liquid.

Among the separated spinels, we found only two which fall into this group. In one of these, SP5, the core and rim differ sharply not only in $\mathrm{Cr}_{2} \mathrm{O}_{3}$. $\mathrm{TiO}_{2}$, and $\mathrm{V}_{2} \mathrm{O}_{3}$ contents but also in their $\mathrm{TiO}_{2} / \mathrm{V}_{2} \mathrm{O}_{3}$ ratios (Fig. $7 \mathrm{C}$ ). This feature. along with the corroded core (Fig. $t h$ ). requires at least a two-stage history: formation of the $\mathrm{C} r$-poor core, followed by reaction with the surrounding medium and deposition from it of the Cr-rich layers.

\section{Cherron-type grains}

Among the separated spinels, three grains of this type (SP44, SP50, and SP76) have only two or three zones, like olivine crystals in some chondrules in Semarkona (JONES, 1990). The remaining chevron-type grains and SP5, with their multiple layers of varying $\mathrm{Cr}_{2} \mathrm{O}_{3}$ contents, may be analogous to orthopyroxenes with oscillatory $\mathrm{FeO}$ zoning found in a Semarkona chondrule by JoNES (1993). Because it is unlikely that a molten chondrule would experience repeated additions of material, or repeated changes in physicochemical conditions while still molten, the oscillatory zoning probably reflects formation of boundary layers which were alternately enriched and depleted in $\mathrm{FeO}$ because crystal growth was faster than diffusion (e.g., Sibi. Y et al.. 1976). The chevronzoned spinel grains discussed here could have formed this way, although no observations of such spinel grains have ever been reported from chondrules.

Gas-solid condensation is also a possible origin for the chevron-zoned grains, because a crystal could easily be exposed to multiple changes in temperature and oxygen fugacity in a nebular environment. This mode of origin is not straightforward, however, for several reasons. During equilibrium condensation from a gas of solar composition, the first spinel to condense should do so prior to forsterite and should be pure $\mathrm{MgAl}_{2} \mathrm{O}_{4}$ (GroSSMAN, 1972). At equilibrium, this spinel reacts with the gas, gradually increasing its $\mathrm{Cr}$ content with falling temperature. This process should cause $\mathrm{Cr}$ to increase gradually from core to rim, and such a trend is not observed in the concentrically zoned grains considered here.

In addition. new calculations show that this method would not yield spinel with the high $\mathrm{Cr}$ and $\mathrm{Fe}$ contents that are 
characteristic of the separated spinel grains. The same computer program used by LATTIMER and GROSSMAN (1978) was employed in this work to calculate the relative proportions and compositions of minerals that would condense at complete chemical equilibrium from a cooling gas of solar composition. For these calculations, the thermodynamic data used by LATTIMER and GROSSMAN (1978) were updated with free energy data for most silicate and oxide phases from ROBIE et al. (1978), anorthite and gehlenite from ROBINSON et al. (1982), and hibonite and $\mathrm{CaAl}_{4} \mathrm{O}_{7}$ from GEIGER et al. (1988). For diopside and akermanite, the data of ROBIE et al. (1978) were corrected for revised enthalpies of formation from CHARLU et al. (1978) and CHARLU et al. (1981), respectively. Free energy data for $\mathrm{MgAl}_{2} \mathrm{O}_{4}$ are taken from CHAMBERLIN et al. ( 1991 and pers. commun.). Lack of thermodynamic data for $\mathrm{FeAl}_{2} \mathrm{O}_{4}$ and $\mathrm{FeCr}_{2} \mathrm{O}_{4}$ prevented LATTIMER and GROSSMAN (1978) from investigating the composition of condensate spinel. For $\mathrm{MgCr}_{2} \mathrm{O}_{4}, \mathrm{FeCr}_{2} \mathrm{O}_{4}$, and $\mathrm{FeAl}_{2} \mathrm{O}_{4}$, the work of SACK and GHIORSO (1991) was used for the enthalpy and entropy of formation from the elements at $298 \mathrm{~K}$ and for the heat capacity versus temperature function. Ideal solution was assumed for the spinel. According to R. O. Sack (pers. commun.), this is an excellent assumption for all spinel compositions encountered in this work. When it is assumed that the identity of the divalent ion entering the spinel structure is independent of the identity of the trivalent ion, thermodynamic data are required for only three of the four spinel components discussed here in order to specify the spinel composition completely. Measurement errors in the free energies of each of the spinel endmember components lead, however, to inconsistencies between them, such that the spinel composition predicted here at a given pressure and temperature depends on which three of the four components are used in the computations.

Results of these calculations are very similar to those of LATTIMER and GROSSMAN (1978), except that the appearance of spinel in the condensation sequence at a total pressure of $10^{-3} \mathrm{~atm}$ is delayed by $\sim 55^{\circ}$, until $1476 \mathrm{~K}$ where spinel forms by complete reaction of hibonite with the gas and joins the pre-existing condensates, perovskite and melilite. Depending on which spinel components are used, the atomic $\mathrm{Cr} /(\mathrm{Cr}+\mathrm{Al})$ ratio of the spinel is $1.6-3.5 \times 10^{-3}$ at 1470 $\mathrm{K}$ and gradually increases to $1.2-2.6 \times 10^{-2}$ at $1415 \mathrm{~K}$, the temperature at which spinel disappears by reaction with the gas to form anorthite. Over this temperature interval, the atomic $\mathrm{Fe} /(\mathrm{Fe}+\mathrm{Mg})$ ratio gradually falls from 1.0-4.9 $\times 10^{-3}$ to $4.5 \times 10^{-4}-2.1 \times 10^{-3}$. At $10^{-4}$ atm total pressure, the maximum $\mathrm{Cr} /(\mathrm{Cr}+\mathrm{Al})$ is $2.8 \times 10^{-2}$ and the maximum $\mathrm{Fe} /(\mathrm{Fe}+\mathrm{Mg})$ is $1 \times 10^{-3}$. According to these calculations, spinel grains that condensed at equilibrium from a gas of solar composition should contain no less than $97 \mathrm{~mol} \%$ $\mathrm{MgAl}_{2} \mathrm{O}_{4}$, with no more than $3.0 \mathrm{wt} \% \mathrm{Cr}_{2} \mathrm{O}_{3}$ and $0.30 \mathrm{wt} \%$ $\mathrm{FeO}$. Regardless of their zoning patterns, the vast majority of the spinel grains described in this paper could not have formed in this way.

Perhaps condensation of spinel was metastably delayed or continued until $\mathrm{Cr}$-rich spinel could condense, and the olivine acted as a nucleus for crystallization. Our calculations suggest that if spinel were to continue to condense, rather than react with the gas to form anorthite, the $\mathrm{Cr}$ content of spinel would continue to increase. The high Fe contents in spinel would remain a problem, however, because a solar gas is sufficiently reducing that very little FeO is expected at these high temperatures.

\section{Patchy grains}

Exsolution is an unlikely explanation for the patchy zoning patterns reported here, although the textures are similar to those described by MUIR and NALDRETT ( 1973 ) and attributed by them to exsolution. Those samples, however, contain very wide ranges of $\mathrm{Al}_{2} \mathrm{O}_{3}\left(4-40 \mathrm{wt} \%\right.$ ) and $\mathrm{Fe}_{2} \mathrm{O}_{3}$ (e.g., 7-50 $\mathrm{wt} \%)$, and the existence of a large miscibility gap below $900^{\circ} \mathrm{C}$ for spinels of such compositions has been known for some time (e.g., TURNOCK and EUGSTER, 1962; LEHMANN and Roux, 1986). These gaps are also predicted from thermodynamic data (LEHMANN and ROUX, 1986: SACK and GHIORSO, 1991). For the compositions observed in the patchy Murchison spinels, no miscibility gaps have been observed experimentally and only very small gaps are predicted between $\mathrm{Mg}$-. Al-rich and Fe-, $\mathrm{Cr}$-rich spinel, but at temperatures below $\sim 500^{\circ} \mathrm{C}$. Application of the olivine-spinel geothermometer (ENGI, 1983) to our samples (where possible), gives temperatures of $600^{\circ} \mathrm{C}$ or more in all cases. Furthermore, comparison of the data for patchy spinels with the calculated curves of SACK and GHIORSO (1991) shows that, with a maximum $\mathrm{Cr} \#$ of 0.30 and a minimum $\mathrm{Mg} \#$ of 0.68 , all analyses of the patchy spinels plot on the $\mathrm{Mg}$-rich, Al-rich sides of the calculated miscibility gaps, not on opposite sides. as would be the case if the patches formed by exsolution of immiscible components.

Because spinels with compositions within the above ranges are miscible, the patchy textures cannot be primary equilibrium textures, because the two different compositions of spinel cannot crystallize from the same liquid or gas. Plagioclase with patchy zoning has been observed in terrestrial igneous rocks (VANCE, 1965; ANDERSON, 1984). The patches are more sodic (i.e., more fractionated) than, and have sharp boundaries with, the host crystals, and in some cases individual patches are concentrically zoned (VANCE, 1965). Thesc patchy feldspars probably formed by igncous crystallization followed by partial resorption, and then deposition of relatively fractionated feldspar in the cavities created by resorption (VANCE, 1965; ANDERSON, 1984). This model does not work for the patchy Murchison spinels, however. Some grains have $\mathrm{Cr}$-poor patches and others have $\mathrm{Cr}$-rich ones, so the patches and hosts do not have a consistent composition relationship, as in the patchy feldspars described above. HuTCHEON et al. (1978) reported patchy zoning of $\mathrm{Na}$ and $\mathrm{Mg}$ in anorthite in several Allende CAIs, which may be the result of metasomatism (I. D. Hutcheon, pers. commun.). If correct, metasomatism would be a possible explanation for the patchy zoning in spinel, but no convincing models have been presented.

Because it therefore seems unlikely that the patchy spinel grains were ever molten, we conclude that these grains most likely formed by sintering of aggregates of smaller, probably condensate, spinel grains which were enriched in $\mathrm{Cr}$ and probably Fe to varying degrees. Although most contacts between $\mathrm{Cr}$-rich and $\mathrm{Cr}$-poor patches are blurred, the hetero- 
geneities in $\mathrm{Cr}$ (and $\mathrm{Al}$ ) have been largely preserved while those in $\mathrm{Fe}$ (and $\mathrm{Mg}$ ) have been mostly erased by diffusion during heating (see, e.g., Fig. 5). Although not proven experimentally, there have been previous suggestions that $\mathrm{Cr}$ $\mathrm{Al}$ diffusion is slower than that of $\mathrm{Mg}$ and $\mathrm{Fe}$ in $\mathrm{Cr}$-spinel. FUDALI and NOONAN (1975) suggested this based on much wider ranges in $\mathrm{Cr} / \mathrm{Al}$ ratios than in $\mathrm{Mg} / \mathrm{Fe}$ ratios in spineis in Gohabeb and Mezö-Madaras. MCCOY et al. (1991) found this consistent with their observations as well. They concluded that the Al-Cr zoning in the spinels they analyzed was primary, whereas the Fe-Mg- $\mathrm{Zn}$ zoning could have been altered during metamorphism.

Thte sintering model can explain several features of the patchy spinel grains. Derivation of the patches from individual grains with square-to-rectangular cross-sections and different compositions would explain why some grains, such as SP60 (Fig. 1b), have square- to rectangular-shaped patches. In some cases, as in SP4, 7-20, and MI, coarse olivine was present at the time of heating, and it became rounded, with spinel tending to enclose it. The concave indentations in the spinel give it an elongated, scalloped outline against adjacent silicates, reminiscent of "holly-leaf"-shaped spinels, which are observed in some partially recrystallized ultramafic xenoliths and are thought to form by clumping of smaller, interstitial spinels during recrystallization (e.g.. PIKt and S(HWARZMAN, 1977). Compare, for example, the rounded olivine partially enclosed by spinel in M1 (Fig. 2a), 4377-1 (Fig. 2b), and 7-20 (Fig. 2c,d) with the angular, subhedral olivine partially enclosed by spinel in chondrules with probable primary textures (Fig. 1 1a,b) and in SP73 (Fig. 11c). Exsolution of high- and low-Ca pyroxene from each other and of $\mathrm{Fe}$ from olivine in 4377-1 are also indicative of reequilibration in that inclusion. Thus, recrystallization of an olivine-bearing assemblage is consistent with the observed textures and does not require formation of olivine before spinel. In two places where patchy spinel is in contact with the meteorite matrix (Fig. $2 a, c$ ), there is no relationship between the distribution of the patches and the matrix. indieating that the patchiness formed prior to accretion of Murchison, which is also consistent with this model.

Patchy spinel grains may be the end products of sintering of spinel-rich aggregates which originally consisted of many small grains with different compositions. We found several, unsintered, apparently loosely packed, spinel-rich aggregates in Murchison, including one (Fig. 13a) that is $\sim 130 \times 100$ $\mu \mathrm{m}$ and consists of $-90 \%$ spinel and $-10 \%$ olivine, with minor amounts of aluminous diopside. Most of the spinel and olivine grains are $5-10 \mu \mathrm{m}$ across. As shown in Fig. $13 \mathrm{~b}$. some of the spinel grains in the inclusion, like those in the separates, have round cavities and, like the one at the bottom of Fig. 13b, inclusions of Ca-silicate (too small to analyze in this case). There are gaps between most of the grains but. at the center of Fig. $13 \mathrm{~b}$, there are several grains connected to others. Individual spinel grains are homogeneous but, for the whole inclusion, $\mathrm{Cr}_{2} \mathrm{O}_{3}$ contents in the spinel grains range from 1.0 to $1.6 \mathrm{wt} \%, \mathrm{FeO}$ ranges from 0.8 to $7.9 \mathrm{wt} \%$, and the olivine composition is Fog9-F $_{95}$. It seems reasonable to suggest that, if such an aggregate were heated sufficiently, the individual grains would grow together into a single, heterogeneous one with some of the gaps between precursor grains and some of the holes in them partially to completely filled with aluminous diopside or other material. Samples SP58 (Fig. 13c) and SP60 (Fig. 1b) may represent an intermediate step in the sequence from a loose aggregate (Fig. $13 \mathrm{a}, \mathrm{b}$ ) to at patchy grain with some gaps and former grain boundaries to a less porous patchy grain. e.g. SP51 (Fig. 10) and SP64 (Fig. 1d).

Electron probe data show that the patches do not appear to represent two distinct populations of precursor grains. The high-Cr and low-Cr patches vary in composition from grain to grain (Table 1 ) and, within individual grains. composition gaps are small to nonexistent whether the contacts between the grains are sharp or diffuse (Fig. 5). Their minor element contents may overlap (Fig. 5 b), or they may be suggestive of mixing between $\mathrm{Cr}$-, Ti-, $\mathrm{V}$-rich and $\mathrm{Cr}$-, Ti-, $\mathrm{V}$-poor spinel (Fig. 5d). Patches probably represent a wide variety of precursor grains that have been modified to varying degrees by diffusion

\section{Thermal I Histories}

The presence of zoned and unzoned spinels in Murchison suggests that either heating occurred prior to accretion of the meteorite or unzoned grains were never zoned. The zoned. grains that are the most likely to have been modified the least are SP27 (gradational) and SP49 (chevron). Their zoning is probably primary because they are the grains with the strongest zoning in $\mathrm{Mg}$ and $\mathrm{Fe}$, which is relatively easily erased by heating. $\mathrm{FeO}$ is expected to increase from core to rim in spinel either due to increased concentration in a residual hiquid, as seen in spinel in some chondrules, or to increased availability via condensation from a cooling gas. $\mathrm{Cr}_{2} \mathrm{O}_{3}$ should increase in spinel during condensation from a solar gas, but can either increase or decrease during crystallization from a liquid, depending upon the liquid composition and the bulk erystal, liquid distribution coefficient of the crystallizing assemblage. In both unequilibrated spinels. Fe and $\mathrm{Cr}$ are positively correlated.

Among the patchy spinels, the fact that most have patches with diffuse boundaries, some have sharp boundaries. and a few. e.g. SP41. have both. suggests that these grains have experienced a variety of thermal histories. Presumably those with diffuse boundaries were exposed to higher temperatures and/or heated longer than those with sharp boundaries. In those with both types of contacts, the sharp patches may have formed by mild heating following addition of more spinel grains to an earlier-formed aggregate. The effects of diffusion can be seen in the data for SP51 (Fig. $5 \mathrm{c}, \mathrm{d}$ ). The Fe/ $\mathrm{Mg}$ ratios of the patches are uniform but the minor element zoning is preserved. Unfortunately, not enough is known about diffusion rates in spinels of these compositions to allow us to estimate temperatures or cooling rates.

It is unlikely that spinel would be melted upon reheating because of its high melting point, but included silicate might and, if cooled quickly enough, could give rise to the glass inclusions observed in several patchy grains. These glasses are $\mathrm{SiO}_{2}-, \mathrm{CaO}-$, and $\mathrm{Al}_{2} \mathrm{O}_{3}$-rich and $\mathrm{MgO}$-poor (Table 5). Liquids with these compositions would be in equilibrium with anorthite, not spinel. They probably do not represent trapped parental melts, but could be quenched melts of silicate inclusions that were present at the time of heating. 

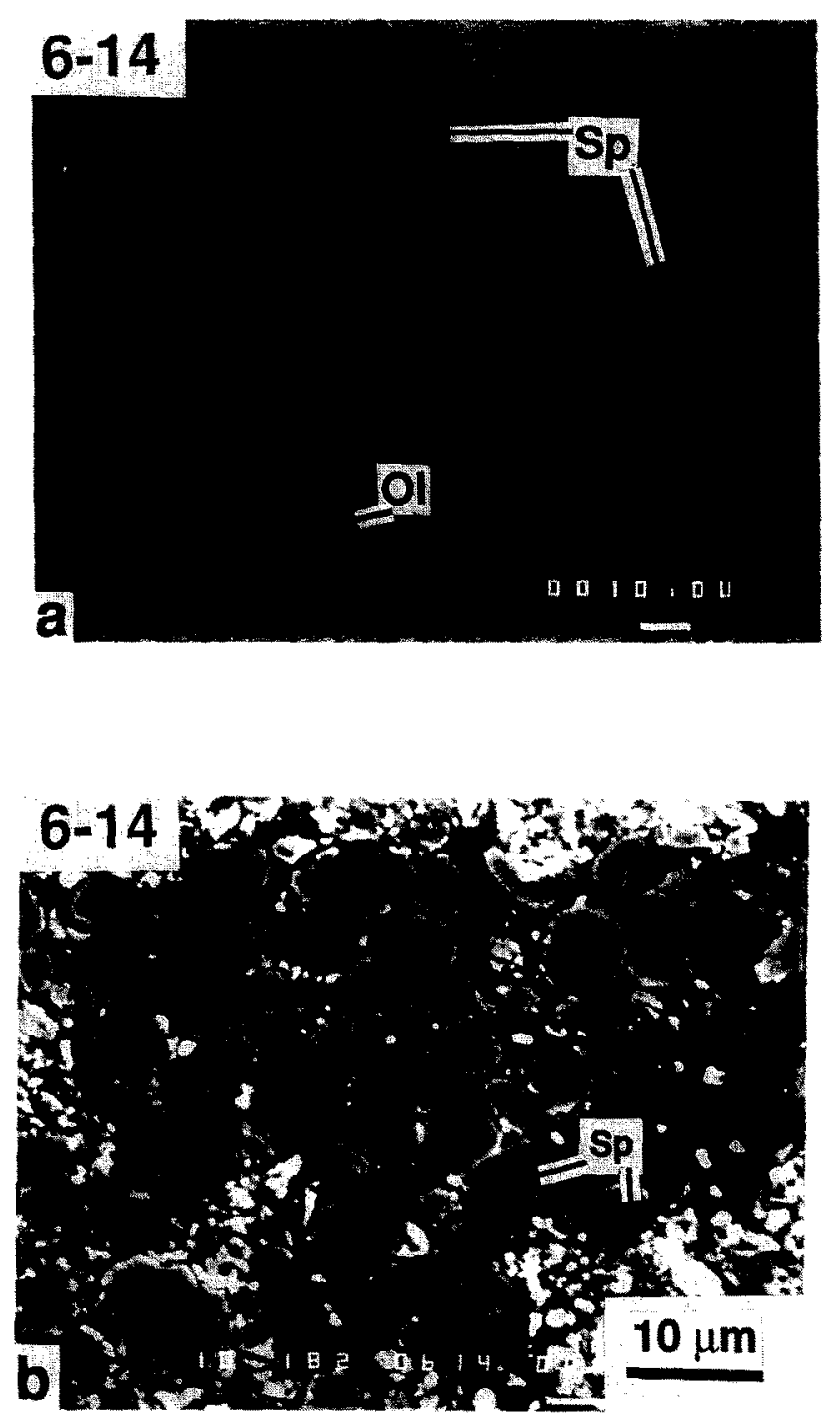

\section{Isotopic Histories}

According to their oxygen isotopic compositions, there exist at least two types of spinel in Murchison. The oxygen isotopic composition of the $\mathrm{Cr}$-rich spinel grains of this study is close to normal with an average composition of $\delta^{17} \mathrm{O}=-0.9$ $\pm 1.4 \%$ and $\delta^{18} \mathrm{O}=1.9 \pm 2.4 \%$. In contrast, the average oxygen isotopic composition of nine pure $\mathrm{Mg}$-, Al-spinel grains from Murchison acid residue CFOc is $\delta^{17} \mathrm{O}=-49.4$ $\pm 1.5 \%$ and $\delta^{18} \mathrm{O}=-49.9 \pm 3.1 \%$ (VIRAG et al., 1991). The latter spinels probably originate in refractory inclusions, as IRELAND et al. ( 1992) found oxygen isotopic compositions comparable to theirs in spinels from spinel-hibonite and spinel-perovskite inclusions from Murchison.

The composition of the spinel-rich residue $2 \mathrm{C} 10 \mathrm{c}\left(\delta^{17} \mathrm{O}\right.$ $\left.=-41.1 \% ; \delta^{18} \mathrm{O}=-39.8 \% \%\right)$ measured by CLAYTON and MAYEDA (1984) would thus represent a mixture of these two components. If we assume that only these two classes of spinel contribute to the oxygen analyzed by CLAYTON and MAYEDA (1984), we calculate a ratio of ${ }^{16} \mathrm{O}$-rich, $\mathrm{Mg}$-, Al-spinel to isotopically normal, $\mathrm{Cr}$-rich spinel of $4.6 \pm 0.7$. This ratio would decrease if hibonite and corundum grains, which are

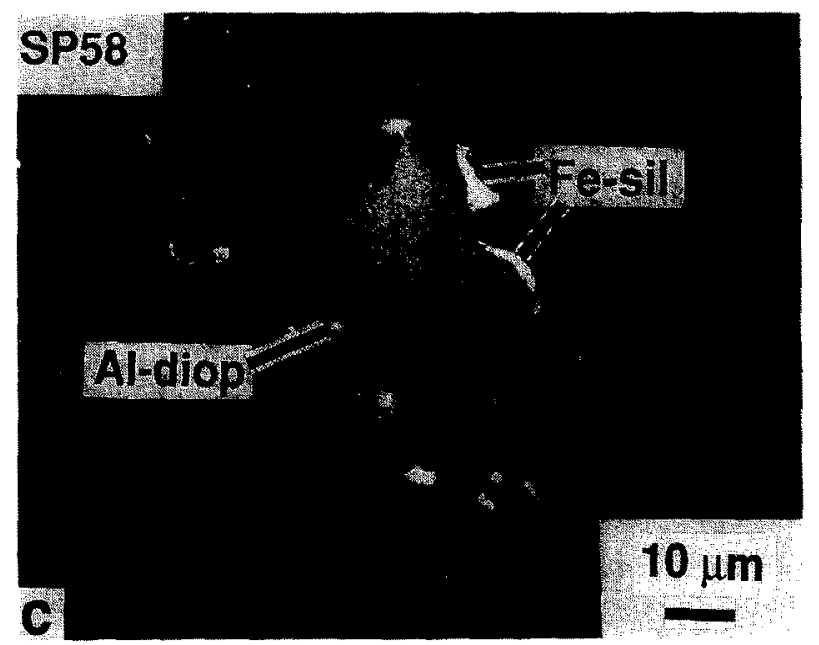

FIG. 13. (a) BEI of spinel-rich aggregate in Murchison, consisting of many small spinel and olivine crystals. (b) Higher-magnification and higher-contrast view of spinel in (a), showing homogeneous spinel grains, some with cavities or silicate inclusions (bright spots). Some grains, such as those at center, are touching, but there are gaps between most grains. (c) BEI of a patchy spinel which has large gaps that may have originally been void space that existed between precursor grains Fe-sil: Fe-silicate. Other abbreviations as used previously.

at least as ${ }^{16} \mathrm{O}$-rich as the Mg-, Al-spinels (FAHEY et al., 1987; VIRAG et al., 1991; IRELAND et al., 1992) and are known to exist in the residues, are taken into consideration. On the other hand, residue $2 \mathrm{C} 10 \mathrm{c}$ may also contain other phases with oxygen that is less ${ }^{16} \mathrm{O}$-rich than the average measured by CLAYTON and MAYEDA (1984). Fe-chromite and Fe-oxide grains have been seen in CFOC (ZINNER and EPSTEIN, 1987; VIRAG et al., 1991) but their abundances in the residue are not known.

A fundamental question is whether or not the oxygen isotopic composition of the Cr-bearing spinel grains of the present study can provide any information regarding the time of their formation. In order to explain the isotopic variations among different mineral phases from Allende Ca-, Al-rich inclusions, CLAYTON et al. (1977) proposed the diffusion exchange model. According to this model, these inclusions were formed with ${ }^{16} \mathrm{O}$ enrichments of approximately $5 \%$ but subsequently some phases, such as melilite, equilibrated with a gas reservoir containing isotopically normal oxygen while spinel retained its original oxygen isotopic composition. Unfortunately, the conclusions that can be drawn from the essentially normal oxygen isotopic composition of the Cr-bear- 
ing spinel grains are limited by the lack of knowledge of their thermal history and of the oxygen diffusion rate in spinel as a function of $\mathrm{Fe}$ and $\mathrm{Cr}$ content. If the time-temperature history of the spinels was similar to those of Allende CAIs it does not seem reasonable to propose that the relatively large $(\sim 100 \mu \mathrm{m})$, patchy spinel grains studied here were able to exchange their oxygen completely, converting original ${ }^{16} \mathrm{O}$ rich compositions to normal oxygen isotopic compositions, while the much smaller $(\sim 30 \mu \mathrm{m})$ spinel grains in the Allende refractory inclusions were unable to do so. However, large Murchison spinels could have cooled much more slowly than Allende CAIs. The model suggested above, for the origin of patchy spinels, envisions their formation by sintering of a pre-existing generation of spinel grains which may have been approximately the same size as those in the Allende inclusions. If the precursor grains were originally ${ }^{16} \mathrm{O}$-rich, their higher $\mathrm{Cr}$ contents could have led to significantly enhanced rates of oxygen diffusion compared to spinel in Allende inclusions, allowing them to exchange with a reservoir of normal oxygen isotopic composition. Although diffusion in chromite spinels is generally faster than in aluminate spinels (BIRCHFNAII, 1968), we do not know whether the substitution of $\mathrm{Fe}$ for $\mathrm{Mg}$ and $\mathrm{Cr}$ for $\mathrm{Al}$ in $\mathrm{Mg}$-, $\mathrm{Al}$-spinel to the extent observed here has any effect on the diffusion coefficient of oxygen. We note that, while SP36 is among the spinel grains with normal oxygen isotopic composition, it has only $1.5-$ $2.0 \% \mathrm{Cr}_{2} \mathrm{O}_{3}$ and $0.5 \% \mathrm{FeO}$ (Table 1).

At this point we cannot determine whether the precursor grains formed initially in a reservoir with isotopically normal oxygen or whether the spinel grains exchanged their originally ${ }^{16} \mathrm{O}$-rich oxygen either because they experienced slow cooling or because the oxygen diffusion in Cr-bearing spinel is significantly faster than in pure $\mathrm{Mg}$-, Al-spinel.

A more promising approach is to compare oxygen diffusion with cation diffusion rates. Generally, cation diffusion in oxides is faster than diffusion of oxygen. For example, Al diffuses faster than $\mathrm{O}$ in $\mathrm{Al}_{2} \mathrm{O}_{3}$ (PALADINO and KINGERY, 1962; REDDY and COOPER, 1982) and in MgO (LINDNER and PARFITT, 1957; REDDY and COOPER, 1983). This is in marked contrast to gehlenite, where oxygen diffusion is faster than cation diffusion (MORIOKA et al., 1987), consistent with the ClAYTON et al. (1977) oxygen exchange model for chemically zoned melilite in Allende CAIs. If $\mathrm{Al}$ and $\mathrm{Cr}$ diffuse faster than oxygen also in Cr-bearing spinels, the obvious lack of extensive Al-Cr interdiffusion in the patchy spinel grains would indicate that their oxygen isotopic compositions did not change since their chemical heterogeneities were established. The argument is even stronger if we consider the diffusion of $\mathrm{Fe}$ and $\mathrm{Mg}$. One patchy spinel analyzed for oxygen isotopes (SP31) shows a large range in FeO (Table 1). In pure $\mathrm{Mg}$-, Al-spinel, the self-diffusion coetticient of $\mathrm{O}$ is 6.4 $\times 10^{-15} \mathrm{~cm}^{2} \mathrm{~s}^{-1}$ at $1553^{\circ} \mathrm{C}$ (REDDY and COOPER, 1981; RYERSON and MCKEEGAN, 1993), much lower than that of $\mathrm{Mg}, 8.6 \times 10^{-10} \mathrm{~cm}^{2} \mathrm{~s}^{-1}$, at the same temperature (SHENG et al., 1992). It is likely that oxygen in these spinel crystals has not re-equilibrated since their Fe-Mg distributions were established. While we can tentatively use these relative diffusion rate considerations to rule out oxygen isolopic exchange of these spinel grains after they became chemically heterogeneous, we cannot rule out the possibility that pre- cursor materials condensed from an ${ }^{16} \mathrm{O}$-rich reservoir and then exchanged their oxygen with an isotopically normal reservoir prior to the formation of the observed spinel grains.

The chromium isotopic data support formation of homogeneous, gradational, core-rim and patchy spinel from an isotopically normal reservoir within less than one \%o. This conclusion is quite different from that reached by ESAT and IRELAND (1989) who concluded that chromium in their samples was variably anomalous to a greater extent that observed in any other samples, even FUN (mass Fractionation with UNknown nuclear components) inclusions (Fig. 10b). Anomalies of this magnitude are clearly not present in our data, so our results do not support those of ESAT and IRELAND (1989), even though, on the basis of sample preparation technique, size, color, and mineral chemistry, the spinels studied by ESAT and IRELAND (1989) appear to represent a population indistinguishable from that studied here. It should be noted that the absence of chromium anomalies in our data is compatible with the lack of oxygen isotopic anomalies in these spinels (Fig. 9).

A more subtle question is whether the spinels studied here have chromium isotopic anomalies comparable to those endemic in CAl-hosted spinels (PAPANASTASSIOU, 1986; BIRCK and ALLĖGRE, 1988), indicated by the box in Fig. 10a. Because of the larger errors involved in single-grain measurements, it is difficult to address the question on a grain-bygrain basis. Taken in aggregate, our data suggest that the large chromian spinels do not have the endemic chromium anomalies of CAI spinels but, in view of the analytical errors, this is only a suggestion which deserves further study. The endemic ${ }^{54} \mathrm{Cr}$ excess is generally regarded as a nucleosynthetic anomaly, i.e., as a manifestation that these samples formed from a reservoir in which different types of presolar materials, bearing different nucleosynthetic products, were not well mixed. In view of the oxygen isotopic evidence that the chromian spinels could have formed from a more nearly normal (well-mixed) reservoir than spinels from CAIs. absence of ${ }^{54} \mathrm{Cr}$ anomalies is not surprising.

The endemic deficit of ${ }^{53} \mathrm{Cr}$ in spinels from CAls, however, is not generally considered to be a nucleosynthetic anomaly. but a "ghost" of ${ }^{53} \mathrm{Mn}$; some $1-2 \epsilon$ of present normal ${ }^{53} \mathrm{Cr}$ was evidently formed by decay of ${ }^{5.3} \mathrm{Mn}$ (half-life $=3.7 \mathrm{Ma}$ ) which was extant in the early solar system, and early formed materials with low $\mathrm{Mn} / \mathrm{Cr}$ ratios, such as meteoritic spinel, should lack this much ${ }^{5 .} \mathrm{Cr}$

\section{SUMMARY AND CONCLUSIONS}

Uniike the spinets from refractory inclusions, those studied here are coarse and contain weight percent levels of $\mathrm{FeO}$ and $\mathrm{Cr}_{2} \mathrm{O}_{3}$, but have higher $\mathrm{Mg} / \mathrm{Fe}$ and $\mathrm{Al} / \mathrm{Cr}$ ratios than spinel (chromites) from ferromagnesian chondrules. Five zoning types (with respect to their $\mathrm{Cr} / \mathrm{Al}$ ratios) are recognized: patchy, homogeneous, gradational, chevron, and core-rim. Many have inclusions of aluminous diopside and/or partially enclose forsteritic olivine. Neither the high $\mathrm{Cr}$ and Fe contents of the spinels nor the crystallization sequence of spinel after olivine indicated by the textures, if they are primary, are consistent with equilibrium condensation from a gas of solar composition. This sequence is observed, however, in some 
Al-rich chondrules in Murchison, and such chondrules may have been the sources of some of the spinel grains described here. Homogeneous, gradational-zoned, and core-rim spinels have been found in such chondrules, demonstrating that these types of grains can crystallize from liquids. The chevronzoned grains could have formed in chondrules, although no such spinels have ever been reported in a chondrule. An origin by gas-solid condensation is also possible for these grains, but a gas more oxidizing than a solar gas would be required. Patchy spinel grains probably formed from spinel-rich aggregates by solid-state recrystallization during heating, which caused pre-existing spinel grains to grow together and homogenized $\mathrm{Mg} / \mathrm{Fe}$ ratios but caused only minor interdiffusion of $\mathrm{Cr}$ and $\mathrm{Al}$. The spinel grains are isotopically uniform and lack the oxygen and possibly the chromium isotopic anomalies observed in spinels from CAIs, indicating formation from a normal, well-mixed reservoir.

Acknowledgments-We thank the following for loans of Murchison thin sections: A. Brearly (University of New Mexico); I. Casanova (Field Museum of Natural History); M. Prinz (American Museum of Natural History); and I. Steele (University of Chicago). Discussions with J. Beckett and I. Casanova were helpful, as were reviews by A. El Goresy, I. Hutcheon, and G. Lugmair. J. Lattimer performed condensation calculations. S. Yoneda assisted with Fig. 10, and A. Davis with Fig. 12b. This work was supported by NASA grants NAG 9-54 (LG), NAGW-3340 (LG), NAG 9-55 (EZ), and NAG 9-292 (FAP).

\section{REFERENCES}

ANDERSON A. T., JR. (1984) Probable relations between plagioclase zoning and magma dynamics, Fuego Volcano, Guatemala. Amer. Mineral. 69, 660-676.

BIRCHENALL C. E. (1968) Diffusion in oxides: Assessment of existing data and experimental problems. In Mass Transport in Oxides (ed. J. B. WACHTMAN JR. and A. D. FRANKLIN); National Bureau of Standards Special Publication 296, pp. 119-127.

BIRCK J.-L. and ALLÈGRE C. J. (1988) Manganese-chromium isotope systematics and development of the early solar system. Nature 331, 579-584.

BISCHOFF A. and KEIL K. (1983) Catalog of Al-rich chondrules, inclusions and fragments in ordinary chondrites. Spec. Pub. 22. Univ. New Mexico Institute of Meteoritics.

BISCHOFF A. and KEIL. K. (1984) Al-rich objects in ordinary chondrites: Related origin of carbonaceous and ordinary chondrites and their constituents. Geochim. Cosmochim. Acta 48, 693-709.

Chamberlin L., Beckett J. R., and Stolper E. M. (1991) Experimental determination of the free energy of formation of $\mathrm{MgAl}_{2} \mathrm{O}_{4}$ spinel: An important constraint on solar system processes. Lunar Planet. Sci. XXII, 195-196 (abstr.).

Charlu T. V., Newton R. C., and Kleppa O. J. (1978) Enthalpy of formation of some lime silicates by high-temperature solution calorimetry, with discussion of high pressure phase equilibria. Geochim. Cosmochim. Acta 42, 367-375.

Charlu T. V., Newton R. C., and Kleppa O. J. (1981) Thermochemistry of synthetic $\mathrm{Ca}_{2} \mathrm{Al}_{2} \mathrm{SiO}_{7}$ (gehlenite) $-\mathrm{Ca}_{2} \mathrm{MgSi}_{2} \mathrm{O}_{7}$ (åkermanite) melilite. Geochim. Cosmochim. Acta 45, 1609-1617.

Clayton R. N. and MAYEDA T. K. (1984) The oxygen isotope record in Murchison and other carbonaceous chondrites. Earth Planet. Sci. Lett. 67, 151-161.

Clayton R, N., Onuma N., Grossman L., and Mayeda T. K. (1977) Distribution of the pre-solar component in Allende and other carbonaceous chondrites. Earth Planet. Sci. Lett. 34, 209224.

El Goresy A., RAMDOHR P., and TAYLOR L. A. (1971) The opaque minerals in the lunar rocks from Oceanus Procellarum. Proc. 2nd Lunar Sci. Conf., 219-235.

El Goresy A., Prinz M., and Ramdohr P. (1976) Zoning in spincls as an indicator of the crystallization histories of mare basalts. Proc 7th Lunar Sci. Conf., 1261-1279.

ENGI M. (1983) Equilibria involving Al-Cr spinel: Mg-Fe exchange with olivine. Experiments, thermodynamic analysis and consequences for geothermometry. Amer. J. Sci. 283A, 29-71.

ESAT T. M. and IRELAND T. R. (1989) Chromium isotopic anomalies in the Murchison meteorite. Earth Planet. Sci. Lett. 92, 1-6.

Fahey A. J., Goswami J. N., MCKeEgan K. D., and Zinner E. (1987) ${ }^{16} \mathrm{O}$ excesses in Murchison and Murray hibonites: A case against a late supernova injection origin of isotopic anomalies in $\mathrm{O}, \mathrm{Mg}, \mathrm{Ca}$ and Ti. Ap. J. (Lett.) 323, L91-L95.

FISK M. R. and BENCE A. E. (1980) Experimental crystallization of chrome spinel in FAMOUS basalt 527-1-1. Earth Planet. Sci. Lett. 48, $111-123$.

FuCHS L. H., OLSEN E., and JENSEN K. J. ( 1973) Mineralogy, mineral-chemistry and composition of the Murchison (C2) meteorite. Smithsonian Contrib. Earth Sci. 10.

FUDALI R. F. and NOONAN A. F. (1975) Gobabeb, a new chondrite: The coexistence of equilibrated silicates and unequilibrated spinels. Meteoritics 10, 31-39.

Geiger C. A., Kleppa O. J., Mysen B. O., Lattimer J. M., and GroSSMAN L. (1988) Enthalpies of formation of $\mathrm{CaAl}_{4} \mathrm{O}_{7}$ and $\mathrm{CaAl}_{12} \mathrm{O}_{19}$ (hibonite) by high temperature, alkali borate calorimetry. Geochim. Cosmochim. Acta 52, 1729-1736.

Grossman L. (1972) Condensation, chondrites and planets. Ph.D. dissertation, Yale Univ.

Grossman L., ГAhey A. J., and ZinNer E. (1988) Carbon and oxygen isotopic compositions of individual spinel crystals from the Murchison meteorite. Lunar Planet. Sci. XIX, 435-436 (abstr.).

HagGerty S. E. (1972) Luna 16: An opaque mineral study and a systematic examination of compositional variations of spinels from Mare Fecunditatis. Earth Planet. Sci. Lett. 13, 328-352.

Hutcheon I. D., Steele I. M., Smith J. V., and Clayton R. N. (1978) Ion microprobe, electron microprobe and cathodoluminescence data for Allende inclusions with emphasis on plagioclase chemistry. Proc. 9th Lunar Planet. Sci. Conf., 1345-1368.

IRELAND T. R., ZINNER E. K.. FAHEY A. J., and ESAT T. M. (1992) Evidence for distillation in the formation of HAL and related hibonite inclusions. Geochim. Cosmochim. Acta 56, 2503-2520.

IRVING A. J. (1978) A review of experimental studies of crystal/ liquid trace element partitioning. Geochim. Cosmochim. Acta 42, $743-770$.

Johnson C. A. and Prinz M. (1991) Chromite and olivine in type II chondrules in carbonaceous and ordinary chondrites: Implications for thermal histories and group differences. Geochim. Cosmochim. Acta 55, 893-904.

JoNES R. H. (1990) Petrology and mineralogy of Type II, FeO-rich chondrules in Semarkona (LL3.0): Origin by closed-system fractional crystallization, with evidence for supercooling. Geochim. Cosmochim. Acta 54, 1785-1802.

JONES R. H. (1992) On the relationship between isolated and chondrule olivine grains in the carbonaceous chondrite ALHA77307. Geochim. Cosmochim. Acta 56, 467-482.

JONES R. H. (1993) Complex zoning behavior in pyroxene in FeOrich chondrules in the Semarkona ordinary chondrite. Lunar Planet. Sci. XXIV, 735-736 (abstr.).

JONES R. H. and SCOTT E. R. D. (1989) Petrology and thermal history of type IA chondrules in the Semarkona (LL3.0) chondrite. Proc. 19th Lunar Planet. Sci. Conf., 523-536.

KueHner S. M. and Grossman L. (1987) Petrography and mineral chemistry of spinel grains separated from the Murchison meteorite. Lunar Planet. Sci. XVIII, 519-520 (abstr.).

LATTIMER J. M. and GrosSMAN L. (1978) Chemical condensation sequences in supernova ejecta. Moon and Planets 19, 169-184.

LEHMANN J. and ROUX J. (1986) Experimental and theoretical study of $\left(\mathrm{Fe}^{2+}, \mathrm{Mg}\right)\left(\mathrm{Al}, \mathrm{Fe}^{3+}\right)_{2} \mathrm{O}_{4}$ spinels: Activity-composition relationships, miscibility gaps, vacancy contents. Geochim. Cosmochim. Acta 50, 1765-1783.

LiNDNER R. and PARFITT G. D. (1957) Diffusion of radioactive magnesium in magnesium oxide crystals. J. Chem. Phws. 26, 182185.

MacPherson G. J., Bar-Matthews M., Tanaka T., Olsen E., and Grossman L. (1980) Refractory inclusions in Murchison: 
Recovery and mineralogical description. Lunar Plant. Sor. Xl 660-662 (abstr.).

MacPherson G. J., Bar-Matthews M., Tanaka T., Olsen E., and GrosSMAN L. (1983) Refractory inclusions in the Murchison meteorite. Goochim. Cosmochim. Acta 47, 823-839.

macPherson G. J., Grossman l., Hashimoto A.. Bar-Mat. TIIEW'S M., and TANAKA T. (1984a) Petrographic studies of refractory inclusions from the Murchison meteorite. Prec. $15 \mathrm{~h} \mathrm{~h} \mathrm{Lunar}$ Planet. Sci. Conf: J. Geophys. Res. 89 (supplement), C299-C312.

macPherson G. J., Paque J. M., Stolper E., and Grossman L. (1984b) The origin and significance of reverse zoning in melilite from Allende Type B inclusions. J. Goll 92, 289-305

MCCOY 1. J., PUN A., and KEIL K. (1991) Spinel-bearing. Al-rich chondrules in two chondrite finds from Roosevelt County, New Mexico: Indicators of nebular and parent body processes. Moteoritics 26, 301-309.

MC KEEGAN K. D. (1987) Oxygen isotopes in refractory stratospheric dust particles: Proof of extraterrestrial origin. Scienc' 237, 14681471.

MiYamoto M., Furuta T.. FuJII N., MCKay D. S.. LoFGREN G. E., and DUKE M. B. (1993) The Mn-Fe negative correlation in olivines in ALHA77257 ureilite. $J$. Geoph $/ \%$. Res. 98, 5301-5307.

Moriok a M.. YURimoto H., IgUSA T., and Nagasawa H. (1987) Diffusion coefficients of cations and oxygen in synthesized single crystal melilites and their implications to the thermal history of Allende CAI. Lunar Planct. Sc\%. X1\%11I, 665-666 (abstr.).

MuIR J. E. and NALDRETT A. J. (1973) ^ natural occurrence of two-phase chromium-bearing spinels. Canadian Mineral. 11, 930939

Neuvonen K. J.. Ohlson B., Papunen H. häkli T. A.. and RamDOHR P. (1972) The Haverö ureilite. Meleoritics 7. 515-531.

OLSEN E. and GROSSMAN L. (1978) On the origin of isolated olivine grains in Type 2 carbonaceous chondrites. Earth Planet. Sci. Lett. $41,111-127$

OSBORN E. F., DEVRies R. C. Gee K. H. and Kraner H. M. (1954) Optimum composition of blast-furnace slags as deduced from liquidus data for the quaternary system $\mathrm{CaO}-\mathrm{MgO}-\mathrm{Al}_{2} \mathrm{O}_{3}$ $\mathrm{SiO}_{2}$. Trans. AIME 200, 33-45.

OSborn T. W., Warren R. G., SMITH R. H., Wakita H.. Zellmer D. L.. and SCHmitT R. A. (1974) Elemental composition of individual chondrules from carbonaceous chondrites, including Allende. Goochim. Cosmochim. Acta 38, 1359-1378.

PALADINO A. E. and KINGERY W. D. (1962) Aluminum ion diffusion in aluminum oxide. J. Chem. Phys 37, 957-962.

Papanastassiou D. A. (1986) Chromium isotopic anomalies in the Allende meteorite. Ap. J. 308, L27-L 30.

PIKE J. E. N. and SCHWARZMAN E. C. (1977) Classification of textures in ultramafic xenoliths. $J$. Geol 85, 49-6I

Podosek F. A., Prombo C. A., Grossman L., and Zinner E. (1991) Chromium isotopic compositions of individual spinel crystals from the Murchison meteorite. Meteoritics 26, 385-386 (abstr.)

Pouchou J. L. and PICHOIR F. (1984) A new model for quantitative $\mathrm{x}$-ray microanalysis. Part l: Application to the analysis of homogeneous samples. Rech. Aerosp. 1984-3, 13-38.

REDDY K. P. R. and COOPER A. R. (1981) Oxygen diffusion in magnesium aluminate spinel. $J$. Ame'r. Ceram. $S_{0}$. 64, 368-371.

REDDY K. P. R. and COOPER A. R. (1982) Oxygen diffusion in sapphire. J. Amer. Ceram. Soc: 65, 634-638

REDDY K. P. R. and COOPER A. R. (1983) Oxygen diffusion in MgO and $\alpha-\mathrm{Fe}_{2} \mathrm{O}_{3} . J$. Amer. Ceram. Soc. 66, 664-666.

Robie R. A., Hemingiway B. S., and Fisher J. R. (1978) Thermodynamic properties of minerals and related substances at $298.15 \mathrm{~K}$ and 1 Bar ( $10^{5}$ Pascals $)$ pressure and at higher temperatures. USGS Bull. 1452.

ROBINSON G. R., JK., HAAS J. L., JR.. SCHAFER C. M.. and HASEITON H. T., JR. (1982) Thermodynamic and thermophysical properties of selected phases in the $\mathrm{MgO}-\mathrm{SiO}_{2}-\mathrm{H}_{2} \mathrm{O}-\mathrm{CO}_{2}, \mathrm{CaO}$ $\mathrm{Al}_{2} \mathrm{O}_{3}-\mathrm{SiO}_{2}-\mathrm{H}_{2} \mathrm{O}-\mathrm{CO}_{2}$, and $\mathrm{Fe}-\mathrm{FeO}-\mathrm{Fe}_{2} \mathrm{O}_{3}-\mathrm{SiO}_{2}$ chemical systems. with special emphasis on the properties of basalts and their minerai components. LSGS Open-File Repr. 83-70

ROEDDER E. ( 1981 ) Significance of Ca-Al silicate melt inclusions in olivine crystals from the Murchison type 11 carbonaceous chondrite Bull. Minerul 104, 339-353

Russell. W. A. Papanastassion D. A., and lombrello T. A (1978) Calcium isotope fractionation on the farth and in other solar system materials. Geochim (osmochim. Acta 42, 1075-1090.

RYERSON F. J. and MCKEEGAN K. D. (1993) Determination of oxygen self-diffusion in åkermanite. anorthite, diopside and spinel: Implications for oxygen isotopic anomalies and the thermal histories of Ca-Al-rich inclusions feochim Cosmothm sto ton review).

SACK R. O. and GHIORSO M. S. (1991) Chromian spinels as pet rogenetic indicators: Thermodynamics and petrological applica tions. Amor. Mineral 76, 827-847.

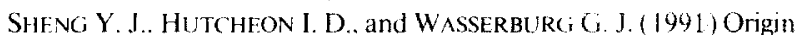
of plagioclase-olivine inclusions in carbonaceous chondrites. 6 er 'him. Cosmodhm. fola 55,581-590.

Sheng Y. J.. Wasserburg G. J.. and Hut (hFon I. D. (1992) Selfdiffusion of magnesium in spinel and equilibrium melts: Constraints on flash heating of silicates. Geothim fosmowhin for 56, $2535-2546$

SHIELDS W. R.. MURPHY T. J., CATANZARO E. J., and (ARNER E. L. (1966) Absolute isotope abundance ratios and the atomic weight of a reference sample of chromium. J. Res. NBS 70A. 193197

Sibley D. F., VOGEL T. A.. WALKER B. M., and BYEREY G. 1976) The origin of oscillatory zoning in plagioclase: $A$ diffusion and growth controlled model. Amer. . Sci. 276, 275-284.

Simon S. B. and GROSSMAN L. (1992) Petrography, composition and origin of chromian spinel crystals separated from the Mur chison meteorite. I.unar Plan'?. Sit. XXIII, 1299-1300 (abstr).

STeEle I. M. (1990) Minor elements in forsterites of Orgueil (C1). Alais (C1) and two interplanetary dust particles compared to $\mathrm{C} 2$ C.3-LOC Forsterites. Mc'coritics 25, 301-307.

STOL.PER E. (1982) Crystallization sequences of Ca-Al-rich inclusions from Allende: An experimental study. Geochin. Cosmochim. Acta 46. $2159-2180$.

TOMEOKA K. and BUSECK P. R. (1985) Indicators of aqueous alteration in CM carbonaceous chondrites: Microtextures of a layered mineral containing Fe, $\mathrm{S}, \mathrm{O}$ and $\mathrm{Ni}$. Gorothm Cosmochim Acta 49, $2149-2163$

TurNoCK A. ( . and Eugster H. P. (1962) Fe-Al oxides: Phase relationships below $1000^{\circ} \mathrm{C}$. J. Petrol. 3, 533-565.

VANCE J. A. ( 1965 ) Zoning in igneous plagioclase: Patchy zoning. I. (ify) 7.3, 636-651

Virag, A., ZiNner E., AMARI S., and ANDERS E. (1991) An ion microprobe study of corundum in the Murchison meteorite: Implications for ${ }^{26} \mathrm{Al}$ and ${ }^{16} \mathrm{O}$ in the early solar system. Grochm. Cosmochim. Acta 55, 2045-206?

YANG H.-Y. (1975) Al- and Ti-rich clinopyroxene in the system $\mathrm{CaMgSi}_{2} \mathrm{O}_{6}-\mathrm{CaAl}_{2} \mathrm{SiO}_{6}-\mathrm{CaTiAl}_{2} \mathrm{O}_{6}$. Proc. (jeol. Soc. China 18, 4858 .

ZINNER E. and EPSTEIN S. ( 1986 ) Heavy carbon in individual oxide grains from Murchison acid residue CFOc. Lumar Plante. Sci. XVII. $967-968$ (abstr.)

ZINNER E. and EPSTEIN S. ( 1987 ) Heavy carbon in individual oxide grains from the Murchison meteorite. Earth Plante. Sci. Lell. 84, $359-368$.

ZinNer E. K.. Calllet C., and El. Goresy A. (1991) Evidence for extrancous origin of a magnesiowustite-metal Fremdling from the Vigarano CV3 chondrite. Earth Planet. Sci. Lell. 102, 252-264. 